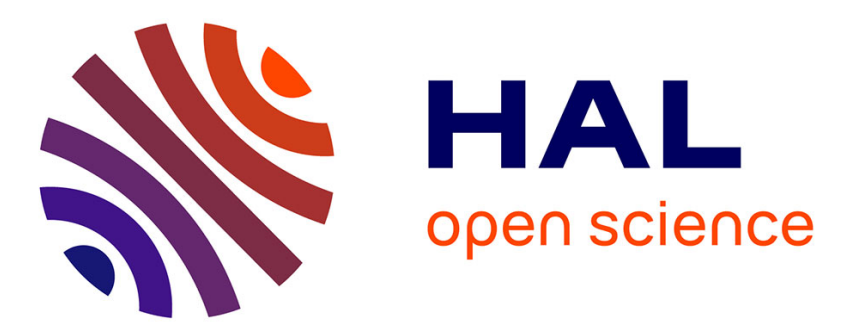

\title{
The Legacy of the Missing Men: The Long-Run Impact of World War I on Female Labor Force Participation Victor Gay
}

\section{To cite this version:}

Victor Gay. The Legacy of the Missing Men: The Long-Run Impact of World War I on Female Labor Force Participation. 2021. hal-02523129v3

\section{HAL Id: hal-02523129 \\ https://hal.science/hal-02523129v3}

Preprint submitted on 6 Sep 2021 (v3), last revised 23 Mar 2023 (v6)

HAL is a multi-disciplinary open access archive for the deposit and dissemination of scientific research documents, whether they are published or not. The documents may come from teaching and research institutions in France or abroad, or from public or private research centers.
L'archive ouverte pluridisciplinaire HAL, est destinée au dépôt et à la diffusion de documents scientifiques de niveau recherche, publiés ou non, émanant des établissements d'enseignement et de recherche français ou étrangers, des laboratoires publics ou privés.

\section{(c)(1)}

Distributed under a Creative Commons Attribution| 4.0 International License 


\title{
The Legacy of The Missing Men The LONG-Run IMPACT OF WORLD WAR I ON Female Labor Force Participation
}

\author{
Victor Gay*
}

September 2021

\begin{abstract}
This article explores the pathways that underlie the diffusion of women's participation in the labor force across generations. I exploit a severe exogenous shock to the sex ratio, World War I in France, which generated a large inflow of women in the labor force after the war. I show that this shock to female labor transmitted to subsequent generations until today. Three mechanisms of intergenerational transmission account for this result: parental transmission, transmission through marriage, and transmission through local social interactions. Beyond behaviors, the war also permanently altered beliefs toward the role of women in the labor force. (JEL J16, J22, N34, Z13)
\end{abstract}

*Toulouse School of Economics (TSE) and Institute for Advanced Study in Toulouse (IAST), University of Toulouse Capitole, Toulouse, France (email: victor.gay@tse-fr.eu). The Data and Supplementary Appendices are available at victorgay.me. I am extremely grateful to Richard Hornbeck for his guidance and support, as well as to James Robinson, Steven Levitt, and Derek Neal. This article has also benefited from fruitful discussions with Ran Abramitzky, Jessica Bean, Michael Becher, Jörn Boehnke, Oliver Browne, Eszter Czibor, Raquel Fernández, Alicia Marguerie, Saurabh Pant, Leah Rosenzweig, Mohamed Saleh, and Estefania Santacreu-Vasut. I thank seminar participants at Chapman, Chicago, the Harris School of Public Policy, Northwestern, PSE, SDU, Stanford, Toronto, TSE, the 2017 EHA, 2018 Galatina, 2019 EHS, and 2019 SYME meetings for helpful comments. I gratefully acknowledge the CISSR and the Department of Economics at the University of Chicago, as well as the ANR under grant ANR-17-EURE-0010 (Investissements d'Avenir program) for financial support. 


\section{Introduction}

Women's involvement in labor markets increased dramatically across industrialized economies after World War II, fundamentally altering the role of women in these societies (Olivetti and Petrongolo, 2016). In France, labor force participation rates of women aged 30 to 49 rose from 40 percent in the early 1960s to 90 percent today. Traditional explanations for this "quiet" revolution have emphasized the role of technological change in increasing both the demand and supply of female labor (Goldin, 2006). ${ }^{1}$ More recently, intergenerational transmission mechanisms have been pointed out as instrumental to this secular transformation. For instance, to account for the endogenous evolution of women's working behaviors and attitudes toward female labor throughout the twentieth century, Fernández (2013) develops a framework of intergenerational learning in which women update their prior beliefs about the payoffs from working by observing women of the previous generation. ${ }^{2}$ Alternatively, in Fernández, Fogli and Olivetti's (2004) model, men who grow up with a working mother form more progressive attitudes toward gender roles. This makes them less averse to having a working wife, thereby providing incentives for women to enter the labor force.

Despite growing consensus that intergenerational transmission mechanisms constitute an important explanation for the revolution of female labor, there is still little empirical evidence that these channels were simultaneously at work throughout the revolutionary period. The main reason concerns challenges to identification. First, most factors that initially induced women to enter the labor force, such as technological change, are strongly persistent. As a result, the working behaviors of women across generations remains largely codetermined. Moreover, the massive entrance of women in the labor force might have altered local labor markets per-

\footnotetext{
${ }^{1}$ Technological explanations include greater availability and declining prices of labor-saving consumer durable goods (Greenwood, Seshadri and Yorukoglu, 2005), oral contraceptives (Bailey, 2006), the fall in child care cost induced by the marketization of home production (Attanasio, Low and Sánchez-Marcos, 2008), improvements to maternal health (Albanesi and Olivetti, 2016), and the structural transformation (Ngai and Petrongolo, 2017). Goldin (1990; 2006; 2014) provides comprehensive accounts of the mechanisms underlying long-run trends in female labor force participation in the United States. For a historical perspective on France, see Maruani and Meron (2012).

${ }^{2}$ Hazan and Maoz (2002), Fogli and Veldkamp (2011), and Hiller and Baudin (2016) construct related models.
} 
manently, making it challenging to identify intergenerational transmission channels independent from these confounding changes.

In this article, I explore the pathways that underlie the diffusion of women's working behaviors across three generations in twentieth-century France. I provide direct empirical evidence that three mechanisms of intergenerational transmission were simultaneously at work: parental transmission, transmission through marriage, and transmission through local social interactions. My empirical strategy exploits a severe exogenous shock to the adult sex ratio: World War I in France. Of 8 million French men drafted during the conflict, 1.3 million died because of the war; a military death rate of 16 percent. As a result, it was not until the 1950s that the adult sex ratio recovered its balance (Figure 1). ${ }^{3}$ This disruption induced many women to enter the labor force shortly after the war: limited pensions to war widows during the 1920s induced many of them to enter the labor force, and deteriorated marriage market conditions induced many single women to become secondary earners in their families while searching longer for a husband (Boehnke and Gay, 2020).

Did this generation of working women pave the way to later generations of women? This article uncovers the channels of intergenerational transmission of this exogenous shock to female labor throughout the second half of the twentieth century, long after sex ratios had reverted to balance and the short-run mechanisms identified in Boehnke and Gay (2020) had become muted. To identify intergenerational transmission independent from confounding changes to local labor market structures, I use an empirical strategy that mirrors the epidemiological approach to culture (Fernández, 2011). This approach implies comparing women born in locations that experienced different military death rates, and therefore different historical shocks to female labor supply, but who reside in the same location and therefore face similar local institutional constraints when making decisions. Applying this approach to all the censuses for which microdata exist, from 1962 to 2012, I find that women born in départements that experienced high (20 percent) rather than low (10 percent) military death rates - equivalent to switching from the 25th to the 75 th percentile of the distribution - were 5 percentage points more likely to

\footnotetext{
${ }^{3}$ World War II affected the adult sex ratio in France only marginally, as 115 thousand French soldiers died because of the war; a military death rate of 1.5 percent (Lagrou, 2002).
} 
be working. ${ }^{4}$ Estimates are stable throughout this 50-year period, though their magnitude declines over time relative to rising trends in female labor force participation rates. Applying an "inverted" epidemiological approach and comparing women with identical origins across rather than within residence locations, I find that intergenerational transmission mechanisms explain half of the long-run impact of WWI military fatalities on female labor force participation.

To account for these findings, I open the black box of intergenerational transmission and explore three channels: parental transmission, transmission through marriage, and transmission through local social interactions. To identify vertical parental transmission, I use the extended annual labor force surveys 2005-2012, which provide origins of respondents' parents. Focusing on the sample of secondgeneration internal migrants, I compare women born and residing in the same département but whose parents were born in départements that experienced different military death rates, and therefore different historical shocks to female labor supply. I find evidence for a strong mother-to-daughter transmission channel: women with mothers born in départements that experienced high (20 percent) rather than low (10 percent) military death rates were 11 percentage points more likely to be working. A 2SLS approach reveals that war-induced changes to mothers' working behaviors drive this maternal transmission. I also find evidence for a father-todaughter transmission channel, though its magnitude is smaller. Next, I explore transmission through marriage and show that women with husbands born in départements that experienced high rather than low military death rates were 2 to 5 percentage points more likely to be working. Consistent with this result, I provide evidence for a strong mother-in-law to daughter-in-law transmission channel. Finally, using municipality-level variation in the exposure to WWI military fatalities among local populations' lineage, I find that this historical shock to female labor transmitted locally and persisted through social interactions. A comparison of these results suggests that mothers and mothers-in-law were of primary importance in the transmission of the legacy of the missing men.

To provide a rationale for the long-run impact of WWI military fatalities on female labor force participation, I argue that women induced to enter the labor

\footnotetext{
${ }^{4}$ Départements represent the second level of subnational government, between régions and arrondissements. Metropolitan France was divided into 87 départements before the war, and 90 after the war. These were further subdivided into 95 départements later on.
} 
force during the interwar period altered preferences and beliefs toward female labor of their daughters, sons, and entourage, and that these changes translated into the working behaviors of women in subsequent generations. Since individuals form preferences and beliefs early in life from learning and socializing with their parents, peers, and neighbors (Hauk and Saez-Marti, 2002; Bisin and Verdier, 2011; Fogli and Veldkamp, 2011; Fernández, 2013; Olivetti, Patacchini and Zenou, 2020), men and women who grew up with a working mother, or in an environment in which many women worked, should form more progressive attitudes toward female labor. ${ }^{5}$ Consistent with this argument, I find that men and women born in départements that experienced greater military death rates hold more progressive attitudes toward the role of women in the labor force today.

Related Literature and Contributions. To account for the revolution of female labor, models of intergenerational transmission typically highlight one specific mechanism - e.g. transmission from mothers to daughters (Fernández, 2011), from mothers-in-law to daughters-in-law (Fernández, Fogli and Olivetti, 2004), or through local information diffusion (Fogli and Veldkamp, 2011). This article is the first to provide comprehensive empirical evidence that these mechanisms were simultaneously at work throughout the revolutionary period, over three generations. For instance, Fernández, Fogli and Olivetti (2004) argue that one explanation for the revolution of female labor is the increasing number of men who grew up with a working mother. They show that women's wartime employment during WWII in the United States (proxied by wartime mobilization) propagated to their daughtersin-law after the war - though Rose (2018) nuances these findings. ${ }^{6}$ Consistent with

\footnotetext{
${ }^{5}$ Many studies find a correlation between both beliefs toward female labor and the working behaviors of mothers and their daughters', of mothers-in-law and their daughters-in-laws', and of mothers and their daughters' peers. Farre and Vella (2013) show that US mothers' attitudes toward gender roles and their working behaviors are correlated with their daughters' attitudes when young and working behaviors when adults, a phenomenon corroborated for Great Britain (Johnston, Schurer and Shields, 2014) and Mexico (Campos-Vazquez and Velez-Grajales, 2014). Olivetti, Patacchini and Zenou (2020) show that the working behaviors of mothers of a woman's friends when growing up affect her own working behavior later in life. Transmission from mothersin-laws' labor choices to their daughters-in-laws' has been found for Japan (Kawaguchi and Miyazaki, 2009), Switzerland (Bütikofer, 2013), the United States (Morrill and Morrill, 2013), and China (Chen and Ge, 2018; Li and Liu, 2018).

${ }^{6} \mathrm{~A}$ large empirical literature suggests that wartime mobilization in WWII U.S. generated an increase in female labor supply after the war (Acemoglu, Autor and Lyle, 2004; Goldin and
} 
this study, I find evidence for a mother-in-law to daughter-in-law transmission channel. But this mechanism constitutes only one among those I am able to identify. ${ }^{7}$ Importantly, in contrast to this study and the broader literature, the empirical strategy I use enables to identify intergenerational transmission independent from confounding changes to local labor market structures. Furthermore, using WWI rather than WWII as a source of variation provides the opportunity to investigate the diffusion dynamics of women's working behaviors across three generations, from the beginning to the end of the revolution of female labor. The case of WWI in France is also particularly advantageous compared to the case of WWII U.S. to explore these mechanisms as black male labor alleviated the consequences of the war on female labor force participation there (Ferrara, 2020).

This article also uncovers mechanisms of historical persistence for which the evidence is still scarce. Due to the methodological focus of the literature on a location-based aspect of history-how historical events in a location shape long-run outcomes in that location - domestic institutions have been pointed out as primary channels of historical persistence (Acemoglu, Johnson and Robinson, 2005; Nunn, 2014; Michalopoulos and Papaioannou, 2017). Partly because of a lack of appropriate data, a crucial vehicle of historical persistence has received less attention: individuals. Understanding how individuals transmit legacies of history across generations requires moving from a location-based approach to a lineagebased approach. Applying this methodology, Michalopoulos, Putterman and Weil (2019) show that pre-modern economic lifeways in Africa still affect individuals' economic outcomes today. ${ }^{8}$ Alesina, Giuliano and Nunn $(2013,524)$ find that half of the overall impact of historical plough use on contemporaneous gender-role attitudes is due to the transmission of cultural norms from ancestors to descendants rather than to long-run changes to institutional structures. Using a more systematic approach, I also show that lineage aspects account for half of the long-run impact of WWI military fatalities on female labor force participation. This im-

Olivetti, 2013; Doepke, Hazan and Maoz, 2015). Using more accurate measurement, Rose (2018) shows that neither manpower mobilization nor WWII military fatalities affected post-war female labor force participation. Instead, female wartime employment marginally affected the intensive margin of post-war female employment in the durable manufacturing sector.

${ }^{7}$ For instance, Fernández, Fogli and Olivetti $(2004,1266-7)$ find no evidence for a mother-todaughter transmission channel.

${ }^{8}$ Nunn and Wantchekon (2011) and Teso (2019, 26-8) use a similar approach. 
plies an important role for individuals relative to local institutional structures in generating historical persistence. My results further suggest that local social interactions are not to be neglected to understand how history transmits through individuals. Additionally, another novelty of this article is the use of a lineage approach within a country's regions to study the transmission of a historical shock. For instance, some specifications compare second-generation internal migrants that originate from neighboring locations. This reduces potential biases that might arise when comparing movers to stayers, which is oftentimes an issue for studies using a lineage approach.

Finally, this article complements the literature that investigates how cultural norms emerge and change over time (Giuliano and Nunn, 2020). Various studies show that historical shocks alter the economic roles of women in subsequent generations, particularly shocks to sex ratios (Giuliano, 2017, 20-23). Teso (2019) finds that sex ratio imbalances generated by the transatlantic slave trade (slaves were predominantly male) induced current generations of women to enter the labor force. Grosjean and Khattar (2019) show that the scarcity of women in nineteenthcentury Australia due to the arrival of predominantly male British convicts had adverse long-run consequences for women's position in the labor force and for attitudes toward gender roles today. A strand of recent studies further explores the long-run consequences of historical shocks to sex ratios on gender roles today, such as the repercussions of the Tripe Alliance War of 1864-1870 in Paraguay (AlixGarcia et al., 2020; Boggiano, 2020) or of the Portuguese Colonial War of 1961-1974 (Cardoso and Morin, 2018). I similarly find that historical sex ratio imbalances had permanent implications for the economic roles of women. However, in contrast to these studies, the historical shock I consider is sharper - it was generated over a period of four years - which enables to rule out alternative channels through which it might have translated over the long run. More importantly, two elements differ substantially in the analysis offered in this article compared to the broader literature. First, the use of both the epidemiological as well as the "inverted" epidemiological approaches enable to disentangle the role of culture from that of institutions. ${ }^{9}$ Second, by examining outcomes continuously over time from the initial shock to

\footnotetext{
${ }^{9}$ Although Alix-Garcia et al. (2020) and Boggiano (2020) use a relatively sharp shock to sex
} ratios, and Teso $(2019,26-8)$ uses the epidemiological approach. 
the present, the long-run exclusion restriction necessary for this type of analysis is much more likely to be satisfied. In particular, results imply that the persistence of the implications of the war has been constant over time and is not dependent upon the time-point selected for the analysis. ${ }^{10}$

In the remainder of the article, I describe the short-run impact of WWI on female labor (Section 2) and show that this shock persisted (Section 3) through mechanisms of intergenerational transmission (Section 4). In Section 5, I show that it also altered attitudes toward female labor. Finally, Section 6 puts the magnitudes of estimates in this article in perspective and concludes. Throughout the article, Figures and Tables indexed by a letter are available in the Online Appendix. A Data Appendix is available on the author's webpage.

\section{The Missing Men and Interwar Female Labor Force Participation}

\subsection{World War I Military Fatalities}

To construct a local measure of military death rates, I collected individual military records for all 1.3 million French soldiers who died because of the war and extracted their dates and départements of birth. ${ }^{11}$ The military death rate in a département is the ratio of deceased soldiers born in the département to the size of its drafted population, which is captured by the male population aged 15 to 44 in 1911 - conscription concerned all men aged 20 to 48. The distribution of military death rates is displayed in Figure 2 in the geography of 1914 (Gay, 2021). Military death rates range from 6 percent in Belfort to 29 percent in Lozère. The average is 15 percent, the 25 th percentile 10 percent, and the 75 th percentile 20 percent. Throughout the article, I interpret regression coefficients by comparing differences in outcomes across individuals from départements that experienced high (20 percent) rather than low (10 percent) military death rates during the war. Echoing national trends displayed in Figure 1, regression analysis confirms that, while dramatic, disruptions to sex ratios remained limited to the interwar period (Figure

\footnotetext{
${ }^{10}$ Several recent studies have highlighted how the past might have time-varying effects on the present, such as Ochsner and Roesel (2019), Cantoni, Hagemeister and Westcott (2020), and Fouka and Voth (2020).

11 Military records are from the Mémoire des Hommes (MDH) archive. The Data Appendix provides more details. This dataset is also used in Boehnke and Gay (2020). Prost (2008) provides a historical account of the assessment of WWI military fatalities in France.
} 
A.1).

Two elements explain the systematic part of the variation in military death rates across départements: the territorial organization of military recruitment and the industrial war effort. The territorial organization of the military structured both recruitment and army corps, which initially comprised soldiers from the same military region. ${ }^{12}$ Soldiers from the same region were therefore sent to the same battlefields at the beginning of the war. ${ }^{13}$ However, as military fatalities soon accumulated, the military command changed its allocation policy; after five months into the war, soldiers were allocated to depleted army corps by priority, effectively pooling soldiers from different regions (Boulanger, 2001, 253). As a result, military death rates varied greatly across départements, even within regions - military region fixed effects explain only 16 percent of the variation in military death rates across départements. ${ }^{14}$

As the war lingered, the military command's plan to supply troops with war matériel proved dramatically insufficient (Porte, 2005; Bostrom, 2016). ${ }^{15}$ To cope with the ongoing war effort, the Ministry of War recalled soldiers with manufacturing skills so that up to 12 percent of soldiers were employed in war factories during the conflict. An additional 8 percent were employed in military administration. ${ }^{16}$ As a result, soldiers from industrial and urban areas were less likely to die in combat than those from rural areas. This pattern clearly emerges when regressing military death rates on pre-war characteristics (Table 1): rural départements experienced greater military death rates, where rurality is captured by the share of rural population and the share of population born in the département. ${ }^{17}$ Rurality explains 75

\footnotetext{
${ }^{12}$ This territorial structure was inherited from the reorganization of the army after the FrancoPrussian War of 1870 . The structure in place in 1914 was defined by the law of December 22, 1913 (Boulanger, 2001, 16-24).

${ }^{13}$ The mobilization plan (Plan XVII), designed in 1912, assigned each army corps to a specific area after invasion by German troops. The structure of this plan was predetermined by the railway network (Gonzalez-Feliu and Parent, 2016).

${ }^{14}$ This measure of military death rates improves upon previous measures used in Abramitzky, Delavande and Vasconcelos (2011) and Vandenbroucke (2014), which are based on Huber (1931) and vary at the level of these 21 military regions.

${ }^{15}$ For example, the Plan XVII procured $13,60075 \mathrm{~mm}$ shells per day. Nearly 40,000 were used daily during the Race to the Sea in October 1914. By then, half of the stock of $75 \mathrm{~mm}$ shells had been depleted (Bostrom, 2016, 264). See also Porte (2005, 73-82).

${ }^{16}$ This allocation policy was enacted by the Dalbiez bill of August 17, 1915. Soldiers were also allocated to steel production and harvesting from 1917 onward.

${ }^{17}$ The census of 1911 defines the share of rural population as the share of population that
} 
percent of the variation in military death rates (column 1). Determinants of subsequent female labor force participation-pre-war female labor force participation, female education, total fertility, personal wealth per inhabitant - as well as additional characteristics are not correlated with military death rates, and only explain an additional 8 percent of their variation (column 2). ${ }^{18}$ Including 19 military region fixed effects explains an additional 6 percent (column 3). Throughout the analysis, I rely on the residual variation in military death rates following the specification in column 3. I interpret this residual variation as non-systematic and related to the randomness at which soldiers encountered violence on the battlefield.

\subsection{Female Labor Force Participation during the Interwar Period}

To assess the short-run impact of WWI military fatalities on women's working behaviors, Boehnke and Gay (2020, 11-6) exploit differential changes in female labor force participation rates before (1901-1911) and after (1921-1936) the war across départements that experienced different military death rates. Their results imply that in départements that experienced high (20 percent) rather than low (10 percent) military death rates, female labor force participation rates were 4 percentage points higher during the interwar period, an increase of 12 percent relative to pre-war levels.

The inflow of women in the labor force occurred after rather than during the war, as départements with greater female wartime employment did not experience a post-war rise in female labor force participation (Boehnke and Gay, 2020, 23-6). Instead, this inflow was driven by increased labor supply by war widows, whose pensions remained limited until the early 1930s, but also by young single women, who had to enter the labor force while searching longer for a husband (Abramitzky et al., 2011; Boehnke and Gay, 2020, 17-21). ${ }^{19}$ In contrast, labor demand factors were

resides in municipalities with fewer than 2,000 inhabitants. The share of population born in the département is tied to fundamental aspects of French rurality as a measure of the intensity of the rural exodus during the late nineteenth century.

${ }^{18}$ These additional characteristics include the share of active population in the agricultural sector, in the industrial sector, average height, total population, the share of literate population, and average direct taxes per inhabitant.

${ }^{19}$ Perturbed conditions on the marriage market were however temporary and circumscribed to the interwar period. Using the family survey of 1954, Boehnke and Gay (2020, Appendix H) show that rates of definitive singlehood among women of the cohorts 1899-1908 were similar across départements with different military death rates, suggesting that women only delayed marriage 
of second-order importance: comparing female wages across sectors with different substitutability between male and female labor, Boehnke and Gay (2020, 21-3) find that substitution of firms from male labor to female labor was likely limited.

\section{The Legacy of the Missing Men}

\subsection{An Epidemiological Approach}

To explore whether this short-run shock to female labor transmitted to later generations, I use an empirical strategy that mirrors the epidemiological approach to culture (Fernández, 2011). Given that the relationship between inherited beliefs and behaviors might be codetermined by institutional factors, this approach identifies intergenerational transmission through the behaviors of individuals with different geographical origins but who reside within the same environment, thereby facing similar constraints when making decisions. ${ }^{20}$

Interwar changes in female labor force participation were driven by increased female labor supply, which slightly depressed female wages in locations that were relatively more affected by the war (Boehnke and Gay, 2020, 21-3). Lower female wages might have incentivized firms to specialize in female labor-intensive activities. Had these changes persisted, the incentive structure faced by women would differ systematically across locations that experienced different military death rates. To identify the portable component of the legacy of the missing men and disentangle intergenerational transmission from confounding institutional factors, I exploit variations in the working behaviors of women who make decisions under similar local labor market conditions but whose geographical origins differ in their exposure to the war.

due to the war.

${ }^{20}$ This approach has been used to identify the role of culture for labor choices of immigrant women to the U.S. (Fernández and Fogli, 2009; Blau, Kahn and Papps, 2011; Gay et al., 2018). 


\subsection{The Population Censuses (1962-2012)}

I combine all the censuses for which microdata exist, from 1962 to $2012 .^{21}$ The necessary information for this study is available for 20 to 25 percent samples of the population (except those of 1962 and 1999, which are 5 percent samples). The baseline regression sample comprises all French internal migrant married women aged 30 to 49, born and residing in metropolitan France - a total of 3.5 million individuals. I focus on this age group to ensure that human capital investments are completed and to abstract from retirement decisions. I restrict the sample to married women because their entrance in the labor force represented the core of the revolution of female labor; the share of working women in this sample increased from 30 percent in the early 1960s to 80 percent in the late 2000s - Figure A.2 displays sample means for labor, fertility, and education outcomes. Internal migrants are individuals who reside in a département that is different from their département of birth. Under this definition, half of married women aged 30 to 49 were internal migrants as of $2012 .^{22}$ Moreover, trends in the proportion of married women among internal migrant women are identical to trends in the proportion of married women among all women (Figure A.3). Internal migrant and non-migrant women are broadly alike along observable characteristics: although they are slightly more educated, internal migrant women are equally likely to be working, were born in départements with similar military death rates, and have the same number of children (Figure A.4). This suggests that sample selection through migration is unlikely to drive the correlation between military death rates and labor market outcomes. Further analyses in Section 3.4.1 support this assertion.

${ }^{21}$ Census years are 1962, 1968, 1975, 1982, 1990, 1999, 2007, and 2012. From 2004 onward, French censuses are conducted yearly on a rotating basis for a fifth of the French population. Rigorous comparisons across censuses can therefore only be made five years apart-see, e.g., (Brilhault and Caron, 2016).

${ }^{22}$ Départements are relatively small: their median radius is 43 kilometers. The median migration distance is 150 kilometers. The Geographical Mobility and Urban Concentration study of 1961 reports that among married women aged 30 to 49, the primary migration motive is family related for two-fifths of them and work related for another two-fifths (Girard, Bastide and Pourcher, 1964). 


\subsection{Empirical Strategy}

I estimate the following specification separately for each census of year $t$ :

$$
\text { employed }_{i b r t}=\beta \text { death_rate }_{b}+\boldsymbol{\alpha} \mathbf{X}_{1911, b}^{\prime}+\boldsymbol{\gamma}_{i} \cdot \boldsymbol{\delta}_{r} \cdot \boldsymbol{\mu}_{1914, b}+\varepsilon_{i b r t},
$$

where employed ${ }_{i b r t}$ denotes whether woman $i$ born in département $b$ and residing in département $r$ is employed. $\mathbf{X}_{1911, b}$ is a set of pre-war controls that capture the systematic determinants of military death rates and subsequent female labor force participation. ${ }^{23} \gamma_{i}$ is a set of year of birth indicators. Consistent with the epidemiological approach, I include département of residence fixed effects, $\boldsymbol{\delta}_{r}$. To further reinforce the credibility of the conditional independence assumption, I include military region of birth fixed effects, $\boldsymbol{\mu}_{1914, b}$ (soldiers from the same military region were initially sent to the same battlefields, making the distribution of military death rates more likely to be idiosyncratic within military regions). I use two-way clustering and cluster standard errors at the levels of départements of birth and residence. Because fixed effects are interacted, $\beta$ is identified from variations in the working behaviors of internal migrant married women of the same cohort, residing in the same département, but who were born in neighboring départements that experienced different military death rates - this corresponds to 24-34 thousand comparison groups depending on the census. ${ }^{24}$

\subsection{Results}

Estimates are reported in Panel a of Figure 3. They imply that women born in départements that experienced high (20 percent) rather than low (10 percent) military death rates were 5 percentage points more likely to be working between 1962 and 2012. They are significant at the 1 percent level and stable across time. Since base rates increased from 30 percent in the early 1960s to 80 percent in the late 2000s, their relative size declined from 14 percent of the mean in 1962 to 5 percent in 2012 (Panel b).

\footnotetext{
${ }^{23} \mathbf{X}_{1911, b}$ contains the share of rural population, the share of population born in the département, female labor force participation, a measure of female education, total fertility, and personal wealth per inhabitant, all measured in 1911.

${ }^{24}$ There were 19 military regions in 1914, containing 5 départements on average - they would be fairly close-by, if not strictly neighboring in most cases (Figure 2).
} 
In the short-run, female labor force participation rates increased by 4 percentage points after the war in départements that experienced high (20 percent) rather than low (10 percent) military death rates (Boehnke and Gay, 2020). The ratio 5/4 can therefore be interpreted as an estimate for the intergenerational transmission of working behaviors from women in the interwar period to women in the post-WWII era. This ratio implies that a 1 percentage point initial increase in female labor force participation due to WWI was associated with a 1.25 percentage point increase in the likelihood of a woman working between 1962 and 2012.

Epidemiological approach vs location-based approach. What was the role of changes to local labor market structures relative to intergenerational transmission in the persistence of this historical shock? First, consider non-migrants. Their behaviors cumulate implications of both transmission of cultural norms and changes to local labor market structures. Here, I repeat the analysis on the sample of non-migrant married women aged 30 to 49 and estimate: ${ }^{25}$

$$
\text { employed }_{i r t}=\beta \text { death_rate }_{r}+\boldsymbol{\alpha} \mathbf{X}_{1911, r}^{\prime}+\boldsymbol{\gamma}_{i} \cdot \boldsymbol{\mu}_{1914, r}+\varepsilon_{\text {irt }} \text {. }
$$

In contrast to the epidemiological approach, this specification does not include residence location fixed effects. As a result, $\beta$ is identified from variations in the working behaviors of women across rather than within départements. I report estimates in Panel a of Figure 4. They imply that women born and residing in départements that experienced high (20 percent) rather than low (10 percent) military death rates were 7 to 11 percentage points more likely to be working between 1962 and 2012. A comparison with estimates in Figure 3 suggests that 43 to 62 percent of the legacy of the missing men operated through intergenerational transmission rather than through changes to local labor market structures.

Second, consider the sample of first-generation internal migrant married women aged 30 to 49 and the following "inverted" epidemiological approach:

$$
\text { employed }_{i b r t}=\beta \text { death_rate }_{r}+\boldsymbol{\alpha} \mathbf{X}_{1911, r}^{\prime}+\boldsymbol{\gamma}_{i} \cdot \boldsymbol{\omega}_{b} \cdot \boldsymbol{\mu}_{1914, r}+\varepsilon_{i b r t},
$$

\footnotetext{
${ }^{25}$ Similar to specification 1 , employed ${ }_{i r t}$ indicates whether woman $i$ residing in département $r$ is employed, $\mathbf{X}_{1911, r}$ is a set of pre-war controls, $\boldsymbol{\gamma}_{i}$ a set of year of birth fixed effects, and $\mu_{1914, r}$ a set of military region fixed effects. Standard errors are clustered at the level of départements of residence.
} 
where $\omega_{b}$ are département of birth fixed effects. Here, $\beta$ is identified from variations in the working behaviors of women across départements but within geographical origins. By fixing variations due to départements of birth, the coefficient solely captures the role of changes to local labor market structures. I report estimates in Panel b of Figure 4. They imply that women born in the same département but residing in départements that experienced high (20 percent) rather than low (10 percent) military death rates were 3 to 7 percentage points more likely to be working between 1962 and 2012. These estimates suggest that 39 to 60 percent of the legacy of the missing men operated through intergenerational transmission rather than through changes to local labor market structures. ${ }^{26}$

Although both analyses use alternative samples and sources of identifying variation, they provide similar answers. These magnitudes are also consistent with results of Alesina, Giuliano and Nunn $(2013,524)$, who find that 35 to 50 percent of the impact of historical plough use on contemporaneous gender-role attitudes is due to the transmission of cultural norms.

\subsubsection{Robustness}

I perform a series of robustness checks that support the credibility of baseline estimates. The full set of results is reported in Appendix B. I also show in Appendix C that World War II military fatalities and destruction do not affect the results.

Alternative Specifications. Estimates are robust to the choice of regression model: marginal coefficients from Probit and Logit models are identical to OLS coefficients. They are also similar when the outcome is a labor force participant indicator, when widening age bounds to 25 to 59 , and when including women of all marital statuses.

Selective Migration Patterns. Because coefficients are identified from behaviors of internal migrants (though originating from neighboring départements), selective migration might account for the results if out-migration patterns were correlated with both military death rates and labor market outcomes. But, as mentioned

\footnotetext{
${ }^{26}$ I build the denominator by summing coefficients from the epidemiological approach and the inverted epidemiological approach in Panel b of Figure 4.
} 
before, both variables are equal across migration status (Figure A.4). A more systematic approach through regressions of observable characteristics on a migration status indicator confirms that internal migrants and non-migrants are similar along these variables, as well as along fertility. Internal migrants are, however, positively selected in terms of education. This source of selection might bias the results if it was operating differently across individuals that originate from départements that experienced low and high military death rates. Reassuringly, including an interaction term between the internal migrant indicator and the military death rate of individuals' départements of birth reveals that selection along all observable characteristics - including education - does not operate systematically differently across départements of birth. These tests suggest that this source of selection cannot account for the main results.

Beyond selection through out-migration patterns, results might be biased through selective in-migration patterns, that is, through the destination location of internal migrants. In particular, individuals born in départements that experienced greater military death rates might settle in more dynamic labor markets. Reassuringly, removing the ten most urban départements of destination from the sample leaves the results unchanged. Still, in-migration selection might operate within destination départements, with those born in départements that experienced greater military death rates sorting systematically into the more dynamic local labor markets. Comparing internal migrants within their local labor market of residence through employment zones and city fixed effects also leaves baseline estimates unchanged, suggesting that in-migration sorting does not account for the results.

To further alleviate potential issues of selective migration patterns, I control for the relative attractiveness of origin and destination départements through dyadic measures that capture pull and push forces between each pair of départements, together with the distance between them. I also restrict the sample to individuals who migrated at least one decade earlier - the one-and-a-half generation - since they might be subject to less biases due to recent migration. Both strategies generate estimates that are slightly lower than the baseline, though not statistically different. Overall, these robustness checks suggest that selective migration cannot account for the results. 
Inaccurate Assignment of Military Death Rates. The epidemiological approach requires regressors to be assigned at the level of geographical origin, i.e., the département in which internal migrants' ascendants were residing during the interwar period. However, censuses do not provide ascendants' départements of birth. I am therefore constrained to assume that départements of birth and origin are identical. Here, I relax this assumption by repeating the analysis on the extended labor force surveys 2005-2012, which provide parental geographical origins. I restrict the sample to internal migrants born before the mid-1960s in the same département as both their parents. These restrictions ensure that these individuals' parents were likely born in the 1920s and mid-1930s and that their départements of birth likely trace to the interwar period. ${ }^{27}$ Estimates are slightly inflated compared to the baseline - though not significantly different - suggesting that inaccurate assignment of military death rates in the censuses creates some attenuation bias through measurement error. ${ }^{28}$

Education and Fertility. Labor market outcomes are endogenous to human capital investment and fertility choices. As a result, these decisions might mediate the relationship between women's working behaviors and WWI military death rates. Controlling for educational attainment and number of children leaves results unchanged, suggesting that the long-run impact of WWI military fatalities was direct rather than mediated by education and fertility choices.

\subsubsection{Further Results}

Further results are reported in Appendix D. Herein, I show that women born in départements that experienced greater military death rates do not make different fertility or education choices, corroborating that these decisions are not mediators. ${ }^{29}$

\footnotetext{
${ }^{27}$ The share of French men (women) born in France that remained in their département of birth was 75.0 (75.2) percent in 1921, 74.7 (74.9) percent in 1926, 74.2 (73.5) percent in 1931, and 73.2 (73.2) percent in 1936 according to the censuses, suggesting limited migration movements between the end of the war and the mid-1930s.

${ }^{28} \mathrm{~A}$ related concern is that départements of birth and childhood might differ. Comparing women with similar migration histories generates results identical to the baseline.

${ }^{29}$ I also ran analyses available upon request showing that women born in départements that experienced greater military death rates do not choose more technical curricula or more malebiased occupations.
} 
These women do not marry at different rates, and when they marry, their husbands do not differ along observable characteristics. This suggests that marriage market desequilibria due to the war highlighted by Abramitzky, Delavande and Vasconcelos (2011) remained circumscribed to the interwar period. I also find little heterogeneity across women with different characteristics (number of children, education, age, marital status). In particular, life-cycle patterns in labor force participation are not affected by WWI military fatalities. I further provide cohort-specific estimates and a placebo test using the male sample.

Next, I combine all thirty-two annual labor force surveys from 1982 to 2013 and run a replication that corroborates results obtained with the censuses. ${ }^{30}$ The analysis of labor force surveys further reveals that women born in départements that experienced greater military death rates are more attached to the labor force, but that this influence on the extensive margin does not translate to the intensive margin as they work shorter hours. A final concern is that although there is no evidence of a mediating role of observable educational attainment, results might be driven by unobserved heterogeneity in human capital. Should this be the case, it would be reflected in wages. Reassuringly, I find that women born in départements that experienced greater military death rates do not earn higher wages.

\section{Intergenerational Transmission Mechanisms}

To account for these results, I explore three mechanisms of intergenerational transmission: parental transmission (Section 4.1), transmission through marriage (Section 4.2), and transmission through local social interactions (Section 4.3). Overall, mothers and mothers-in-law appear as primary agents in the transmission of the legacy of the missing men.

\subsection{Parental Transmission}

I first explore vertical transmission from parents to daughters. I find that women with parents (especially mothers) born in départements that experienced greater military death rates are more likely to work. 2SLS estimates reveal that war-induced

\footnotetext{
${ }^{30}$ I run the same specification as the baseline on a different sample of the same underlying population. In that sense, this is a reproduction test (Clemens, 2017, 327).
} 
changes to mothers' working behaviors drive this maternal transmission.

\subsubsection{Empirical Strategy}

I again rely on an empirical strategy that mirrors the epidemiological approach to culture. Using the extended annual labor force surveys 2005-2012, which provide départements of birth of respondents' parents, I focus on the sample of secondgeneration internal migrant married women aged 30 to 59 with parents born in metropolitan France. More precisely, I restrict second-generation internal migrants to women who reside in their département of birth, but whose mothers and fathers were both born in another département. ${ }^{31}$

Focusing on second- rather than first-generation internal migrants improves the credibility of identification. A typical respondent in the sample has parents born during the 1930s. Their départements of birth therefore plausibly trace to the war (see Footnote 27). Moreover, since the location of second-generation internal migrants was determined prior to their births, results are further less likely to be driven by selective migration. ${ }^{32}$ To determine the role of mothers' origins, I estimate:

$$
\text { employed }_{i m f r}=\beta \text { death_rate }_{m}+\boldsymbol{\alpha} \mathbf{X}_{1911, m}^{\prime}+\boldsymbol{\gamma}_{i}+\boldsymbol{\delta}_{r}+\boldsymbol{\mu}_{1914, m}+\boldsymbol{\omega}_{f}+\varepsilon_{i m f r},
$$

where military death rates death_rate ${ }_{m}$, historical controls $\mathbf{X}_{1911, m}$, and military region fixed effects $\boldsymbol{\mu}_{1914, m}$ are assigned at the level of mothers' départements of birth. $\gamma_{i}$ is a set of year of birth and survey year indicators. Consistent with the epidemiological approach, I include département of residence fixed effects, $\boldsymbol{\delta}_{r}$ (départements of residence and birth are identical as the sample consists of secondgeneration internal migrants). To neutralize the influence of fathers' origins, I further include fathers' département of birth fixed effects $\boldsymbol{\omega}_{f}$. This enables to com-

\footnotetext{
${ }^{31}$ In the extended labor force surveys, among the 168 thousand married women aged 30 to 59 who reside in their département of birth, 32 thousand (19 percent) have mothers born outside their département of birth, 33 thousand (20 percent) have fathers born outside their département of birth, and 15 thousand (9 percent) have both parents born outside their département of birth.

${ }^{32}$ Second-generation migrants and natives are broadly alike: they are equally likely to be employed, have the same number of children, and their mothers were born in départements with similar military death rates. As with first-generation migrants, second-generation migrants are slightly more educated than natives (Table A.1).
} 
pare women whose fathers were born in the same départements. ${ }^{33}$ I cluster standard errors at the levels of départements of residence and mothers' départements of birth.

\subsubsection{Results}

I report results in Table $2 .{ }^{34}$ In column $1, \beta$ is identified from variations in the working behaviors of second-generation internal migrant married women of the same cohort, born and residing in the same département, but whose mothers were born in départements that experienced different military death rates. The estimate is significant at the 1 percent level and implies that women whose mothers were born in départements that experienced high (20 percent) rather than low (10 percent) military death rates were 11 percentage points more likely to be working, 13 percent of the outcome mean. Including fathers' département of birth fixed effects to further isolate the role of mothers' origins decreases the estimate only slightly, suggesting a primary role of maternal relative to paternal transmission (column 2). Restricting the identifying variation to mothers born in neighboring départements through mothers' military region of birth fixed effects similarly has little impact on the estimate (column 3). Finally, I include controls for husband and household characteristics, parental characteristics, as well as respondents' education and number of children (column 4). ${ }^{35}$ Again, the estimate changes little, which increases the credibility that economic factors potentially correlated with mothers' origins are not driving the results.

I then reproduce the estimate of column 3 using an alternative definition of second-generation internal migrants - I include women whose mothers were born in another département, but not necessarily their fathers (column 5). The resulting estimate is slightly lower than the baseline. Given that more than half of women in this sample had fathers born in their own département of birth, these "half-natives"

\footnotetext{
${ }^{33}$ Because the sample size for the extended labor surveys is rather limited-15,095 secondgeneration internal migrant married women aged 30 to 59-I do not include interacted fixed effects. Doing so generates more than 3,000 comparison groups, leaving too little residual variation for identification.

${ }^{34}$ Results are similar when the outcome is a labor force participant indicator (Table A.2).

${ }^{35}$ Husband and household characteristics consist of husbands' incomes, age, age squared, education, an indicator for home ownership, and the number of rooms in the home; parental characteristics include indicators for parents' occupational status and mothers' labor status; education controls consist of indicators for educational attainment.
} 
probably assimilated the local culture of their département, making the impact of their mothers' origins less influential.

Next, I reproduce the analysis with paternal origins (Table A.3). I estimate a specification analogous to 4 in which variables are assigned at the level of fathers' départements of birth, and where I include mothers' (instead of fathers') département of birth fixed effects. The baseline estimate is significant at the 5 percent level and implies that women whose fathers were born in départements that experienced high (20 percent) rather than low (10 percent) military death rates were 8 percentage points more likely to be working (column 1). Once fixed effects for maternal origins, fathers' military regions of birth, and parental, individual, and household characteristics are included, the estimate is still positive but declines substantially and is rather imprecise (columns 2-4). The lesser role of paternal origins can be rationalized by the fact that while fathers are primary role models for their sons, they are less so for their daughters, especially relative to gender roles (Farre and Vella, 2013).

The role of fathers nevertheless obtains to some extent once both parental origins are simultaneously considered. I modify specification 4 and include military death rates of both parental origins, distinguishing between women whose parents were born in the same département from those whose parents were born in different départements. I also include historical controls and military region of birth fixed effects relative to both parental origins and cluster standard errors at the levels of départements of residence, mothers', and fathers' départements of birth. Results are reported in Table A.4. Estimates in column 1 imply that women with parents born in the same département that experienced high (20 percent) rather than low (10 percent) military death rates were 12 percentage points more likely to be working. Coefficients on mothers' and fathers' independent origins add up to the coefficient when both were born in the same département, suggesting that the impact of each parental origin cumulates linearly, with maternal origins being more important. Including parental regions of birth fixed effects along with various controls does not alter the results (columns 2 and 3 ). 


\subsubsection{The Mother-to-Daughter Channel}

The previous section provides evidence for the primary role of maternal origins. The working hypothesis is that the war altered mothers' behaviors and beliefs, which they transmitted to their daughters. Using a 2SLS strategy, I now explore directly whether war-induced changes to mothers' working behaviors transmitted to their daughters. ${ }^{36}$

I first show that WWI military fatalities induced many mothers to enter the labor force - the first stage. I use the sample of second-generation internal migrant married women aged 30 to 59 from the extended labor force surveys 2005-2012 and estimate Specification 4 with the following outcome: whether a woman's mother was working while she was growing up. I report results in Panel a of Table 3. The estimate in column 1 is significant at the 1 percent level and implies that mothers born in départements that experienced high (20 percent) rather than low (10 percent) military death rates were 14 percentage points more likely to have been working when their daughters were growing up. Comparing women whose fathers have identical origins and including controls for husband and household characteristics, parental characteristics, as well as respondents' education and number of children increases the estimate a little (columns 2 and 3 ).

Next, I instrument mothers' working behaviors with military death rates of their départements of birth. Second-stage estimates are reported in Panel B of Table $3{ }^{37}$ These represent estimates of intergenerational transmission from mothers' working behaviors to their daughters'. Estimates controlling for paternal origins imply that a 10 percentage points increase in mothers' labor force participation rates induced by WWI military fatalities generated a 5 percentage points increase in the likelihood of their daughters working (columns 5 and 6). The interpretation arguably relies on the validity of the exclusion restriction as the reduced-form impact of WWI military fatalities might have transmitted from mothers to daughters through channels beyond changes to the working behaviors of mothers. This specification isolates the role of mothers from that of fathers, but other factors might be at work such as

\footnotetext{
${ }^{36}$ Unfortunately, no dataset contains both parental origins and a measure of parental beliefs about gender roles. As a result, the transmission from mothers' beliefs to their daughters' beliefs and behaviors cannot be explored directly.

${ }^{37}$ Results are similar when the outcome is a labor force participant indicator, though slightly less precise (Table A.5).
} 
changes in mothers' beliefs toward female labor (see Section 5). Second-stage estimates therefore provide an upper bound for the role of changes to mothers' working behaviors.

\subsection{Transmission Through Marriage}

Fernández, Fogli and Olivetti (2004) argue that sons of working mothers hold more progressive attitudes toward female labor than sons of stay-at-home mothers, making these men less averse to having a working wife, thereby incentivizing women to enter the labor force in the aggregate. Following this line of reasoning, since men born in départements that experienced greater military death rates are more likely to have grown up with a working mother, they should be more likely to have a working wife. Women whose mothers-in-law were born in départements that experienced greater military death rates should therefore be more likely to work. I show below that this transmission channel played a role in the persistence of the legacy of the missing men: by generating a new type of men-those with working mothers - the war established and perpetuated a more progressive social norm toward female labor.

\subsubsection{Transmission from Husbands to Wives}

To assess the role of husbands' origins, I regress women's working behaviors on the military death rates exposure of their husbands' départements of birth. I isolate the role of husbands' origins from that of their wives' by including wives département of birth fixed effects. This enables to compare women born in the same département but whose husbands were born in different départements. Using the censuses 1962-2012, I restrict the sample to women aged 30 to 49 married with first-generation internal migrant men. I estimate:

$$
\text { employed }_{i h b r t}=\beta \text { death_rate }{ }_{h}+\boldsymbol{\alpha} \mathbf{X}_{1911, h}^{\prime}+\boldsymbol{\gamma}_{i} \cdot \boldsymbol{\delta}_{r} \cdot \boldsymbol{\omega}_{b}+\varepsilon_{i h b r t},
$$

where death_rate ${ }_{h}$ denotes the military death rates exposure of the département of birth of husband $h$ with wife $i . \omega_{b}$ are wives département of birth fixed effects and $\delta_{r}$ département of residence fixed effects. 
I report estimates in Figure $5 .{ }^{38}$ In Panel a, I do not include wives département of birth fixed effects. Coefficients are identified from variations in the working behaviors of first-generation internal migrant married women of the same cohort who reside in the same département but whose husbands were born in départements that experienced different military death rates. Estimates are significant at the 1 percent level and imply that women whose husbands were born in départements that experienced high (20 percent) rather than low (10 percent) military death rates were 4 to 7 percentage points more likely to be working between 1962 and 2012. Including wives département of birth fixed effects to further compare women with identical origins in Panel b decreases estimates by 11 to 41 percent, suggesting a limited role for homogamy in military death rates and assortative matching-I further provide direct evidence for homogamy in military death rates in Appendix E. Including husband and household controls as well as fertility and education barely affects the results (Figure A.6). Moreover, restricting the sample to internal migrant women generates similar estimates (Figure A.7).

Next, I explore the relative role of a woman's origins vis-à-vis her husband's. I distinguish women whose husbands were born in the same département from those whose husbands were born in a different département through indicators same $\mathbf{b}_{b h}$ and $\operatorname{different}_{b h}$. Moreover, because this analysis applies the epidemiological approach to both husbands and wives, I estimate the following specification on the sample of internal migrant women aged 30 to 49 married with internal migrant men:

$$
\begin{aligned}
\text { employed }_{i b h r t} & =\beta_{1} \text { same }_{b h} \cdot \text { death_rate }_{h}+\beta_{2} \text { different }_{b h} \cdot \text { death_rate }_{b} \\
& +\beta_{3} \text { different }_{b h} \cdot \text { death_rate }_{h} \\
& +\boldsymbol{\alpha}_{1} \mathbf{X}_{1911, b}^{\prime}+\boldsymbol{\alpha}_{2} \mathbf{X}_{1911, h}^{\prime}+\boldsymbol{\gamma}_{i} \cdot \boldsymbol{\delta}_{r}+\varepsilon_{i b h r t} .
\end{aligned}
$$

I use three-way clustering and cluster standard errors at the levels of départements of residence and each spouse's département of birth. I report estimates in Figure A.8. Focusing on estimates when spouses' origins are different reveals that women's own origins are quantitatively twice as important as those of their husbands' $-\widehat{\beta}_{3}$ represents 61 percent of $\widehat{\beta}_{2}$ on average. Moreover, similar to parental origins, estimates on spouses' origins linearly cumulates- $\widehat{\beta}_{1}$ about equals the sum of $\widehat{\beta}_{2}$ and $\widehat{\beta}_{3}$.

\footnotetext{
${ }^{38}$ Results are similar when the outcome is a labor force participant indicator (Figure A.5).
} 
Three mechanisms could account for these results. First, husbands from départements that experienced greater military death rates might marry with women that have a higher propensity to work in the first place because they were born in départements that experienced greater military death rates as well - an assortative matching mechanism. Second, being a working woman might have become a more valuable trait on the marriage market, providing incentives for wives to work in the aggregate. And third, these men might assume a larger share of household production, thereby freeing some time for their wives to enter the labor force. The first mechanism plays a limited role, as eliminating homogamy in military death rates only partially decreases the estimates (Panel b of Figure 5; see also Appendix E). I analyze further the reality of the third mechanism in Appendix F. In particular, I explore therein whether men in couples with women from départements that experienced greater military death rates perform relatively more household and childcare tasks. Using data from the Generation and Gender Survey (GGS) of 2005 over a dozen household chores, I find that this is not the case. ${ }^{39}$ The likely remaining explanation for the results in this section is therefore that, consistent with Fernández, Fogli and Olivetti (2004), by creating a new type of men-those with working mothers - the war established and perpetuated a more progressive social norm toward female labor, making women's participation to the labor force a more valuable trait on the marriage market.

\subsubsection{Transmission from Mothers-In-Law to Daughters-In-Law}

I now explore directly the role of mothers-in-law by reproducing the analysis of Section 4.1 on the sample of second-generation internal migrant married women aged 30 to 59. To isolate the role of mothers-in-law from that of own parents and husbands, I augment Specification 4 with fixed effects for both parents' and husbands' départements of birth. This enables to compare women whose parents and husbands have identical origins. I report results in Table 4. In column 1, the coefficient is identified from variations in the working behaviors of second-generation internal migrant married women of the same cohort, born and residing in the same

\footnotetext{
${ }^{39}$ There household tasks include household chores (cooking, dish washing, grocery shopping, ironing, and vacuuming) and childcare (who dresses children, takes them to bed, attends them when they are sick, plays with them, helps them with their homework, and brings them to activities).
} 
département, with husbands born in the same département, but whose mothersin-law were born in départements that experienced different military death rates. The coefficient implies that women whose mothers-in-law were born in départements that experienced high (20 percent) rather than low (10 percent) military death rates were 13 percentage points more likely to be working. Including own parents' départements of birth fixed effects and restricting the identifying variation to mothers-in-law born in neighboring départements slightly increases the estimate to 1.5 (columns 2 and 3). Including controls for husband and household characteristics, parental characteristics, as well as respondents' education and number of children further increases the estimate to 1.6 (column 4).

Estimates in Tables 2 and 4 suggest that mothers and mothers-in-law are equally important agents of intergenerational transmission. Comparing their relative roles more directly by including military death rates of mothers' and mothers-in-law's origins together through a specification analogous to that of Table A.4 confirms this interpretation. I report results in Table A.6. Estimates in column 1 imply that women with mothers and mothers-in-law born in the same département that experienced high (20 percent) rather than low (10 percent) military death rates were 24 percentage points more likely to be working. Coefficients on mothers' and mothers-in-law's independent origins add up to the coefficient when both come from the same département, suggesting again that the impact of each parental origin cumulates linearly. While both maternal origins appear important, estimates for mothers-in-law are slightly larger than those for own mothers, although they are not significantly different. ${ }^{40}$ This result complements those of Fernández, Fogli and Olivetti (2004), who find that mothers-in-law rather than own mothers explain the impact of WWII mobilization rates on female labor force participation in the United States.

\subsection{Local Social Interactions}

The third set of mechanisms I explore is horizontal and oblique transmission through local social interactions. Culture is a locally embedded process and social interactions in culture might materialize in two ways: first, the cultural composition

\footnotetext{
${ }^{40}$ The difference between both coefficients in column 1 is 0.05 with a standard error of 0.88 ; the difference in column 3 is 0.36 with a standard error of 0.73 .
} 
of a neighborhood might affect the relative importance of an individual's own culture as individuals surrounded by many with identical origins might find it easier - or feel pressured - to preserve their culture of origin. Conversely, the cultural composition of a neighborhood might affect individuals' beliefs through a process of cultural assimilation.

I first explore whether the legacy of the war diffused through cultural assimilation at the local level. For each census and municipality, I construct a measure of cultural composition in military death rates. ${ }^{41}$ It is the weighted average military death rates exposure of départements of birth among residents in a municipality: death_rate ${ }_{m}=\sum_{o}$ sh_res $_{o, m} \times$ death_rate ${ }_{o}$, where sh_res ${ }_{o, m}$ denotes the share of residents in municipality $m$ born in département o. Then, I estimate the following specification on the sample of first-generation internal migrant married women aged 30 to 49 :

$$
\text { employed }_{i b m l t}=\beta \text { death_rate }_{m}+\boldsymbol{\alpha} \mathbf{X}_{1911, m}^{\prime}+\boldsymbol{\gamma}_{i}+\boldsymbol{\delta}_{l}+\boldsymbol{\omega}_{b}+\varepsilon_{i b m l t},
$$

where $\mathbf{X}_{1911, m}$ contains pre-war characteristics and is constructed in the same way as death_rate ${ }_{m}$. To compare individuals across neighboring municipalities and alleviate potential issues of spatial sorting, I include local labor market fixed effects $\boldsymbol{\delta}_{l} \cdot{ }^{42}$ I also include département of birth fixed effects $\boldsymbol{\omega}_{b}$ and cluster standard errors at the levels of départements of birth and residence. Estimates are identified from variations in the working behaviors of first-generation internal migrant married women of the same cohort, born in the same département, but residing in neighboring municipalities with different cultural compositions in military death rates. I report results in Panel a of Figure 6. Estimates imply that women who reside in a municipality in which the average military death rates composition was one percentage point higher were 1 to 3 percentage points more likely to be working

\footnotetext{
${ }^{41}$ Censuses contain information on individuals in up to 26 thousand municipalities - there are 36 thousand municipalities in France but the remaining 10 thousand municipalities are too small to be sampled in the censuses as they contain less than 200 residents.

${ }^{42}$ Because the independent variable varies at the municipality level, I can use a narrow definition of local labor markets, with the identifying variation restricted to neighboring municipalities. Specifically, I use canton fixed effects. Cantons represent the fourth level of subnational government, between arrondissements and communes. There were about four thousand cantons before 2013, containing nine municipalities on average.
} 
between 1968 and 2012. ${ }^{43}$ Including controls for husband and household characteristics as well as respondents' education and number of children has little effect on the estimates (Figure A.9, Panel a).

Next, I analyze whether the legacy of the war was culturally preserved because of geographical clustering of individuals with similar origins. Again, I restrict the identifying variation to neighboring municipalities and estimate:

$$
\begin{aligned}
\text { employed }_{i b m l t} & =\beta \text { sh_res }_{b, m} \times \text { death_rate }_{b}+\alpha \text { sh_res }_{b, m} \\
& +\boldsymbol{\gamma}_{i}+\boldsymbol{\delta}_{l}+\boldsymbol{\omega}_{b}+\varepsilon_{i b m l t},
\end{aligned}
$$

where sh_res ${ }_{b, m}$ denotes the share of residents in municipality $m$ born in département $b$, the same as the respondent's. This specification includes département of birth fixed effects $\boldsymbol{\omega}_{b}$ so that the coefficient on the interaction term is identified from variations in the working behaviors of first-generation internal migrant married women of the same cohort, born in the same département, but residing in neighboring municipalities. It indicates whether the impact of WWI military fatalities was relatively stronger among women surrounded by more people from their own département of birth. I report results in Panel b of Figure 6. Estimates imply that women born in the same département who reside in a municipality in which the share of residents from their own départements of birth was one percentage point higher were 1 to 2 percentage points more likely to be working. Again, including controls has little effect on the estimates (Figure A.9, Panel b).

Results in this section highlight the role of local social interactions for longrun historical processes. While cultural assimilation affects the diffusion aspect of history, cultural preservation affects its persistence. Both channels empirically work toward the manifestation of the legacy of the war in contemporaneous France. These channels need not oppose each other however: merging specifications 7 and 8 results in estimates that change little, suggesting some degree of orthogonality between the two processes (Figure A.10). These results shed a new light on the dichotomy between culture and institutions. Given the local embeddedness of cul-

\footnotetext{
${ }^{43}$ The coefficient is close to zero and not significant for the census of 1999, the census that contains the least observations in the sample. Because preferences and beliefs are formed while growing up, I assign the cultural composition using the previous census, so the census of 1962 is not part of the analysis. Using contemporaneous measures or a lag of two censuses generates similar results.
} 
ture and mechanisms of horizontal transmission through local social interactions, estimates from a location-based approach - or an "inverted" epidemiological approach (Section 3.4) - might partly capture implications of the local embeddedness of culture rather than solely differences in inherited institutional structures.

\section{Changes to Preferences and Beliefs Toward Female Labor}

To account for results on working behaviors, I argue that women induced to enter the labor force during the interwar period because of WWI altered preferences and beliefs toward female labor of their daughters, sons, and entourage, and that these changes translated into the working behaviors of women in subsequent generations. Since individuals form preferences and beliefs early in life from learning and socializing with their parents, peers, and neighbors (Bisin and Verdier, 2011; Fogli and Veldkamp, 2011; Fernández, 2013; Olivetti, Patacchini and Zenou, 2020), men and women who grew up with a working mother, or in an environment in which many women worked, should form more progressive attitudes toward female labor.

To explore the validity of this argument, I analyze the long-run implications of WWI military fatalities for attitudes toward gender roles. Before delving into contemporaneous data, however, it is worth noting that there were no pre-WWI difference in attitudes toward female labor across départements that experienced different military death rates - at least, no difference as captured by the support to the extension of suffrage and eligibility to women in labor courts (conseils de prud'hommes) in 1901 or support to the extension of political suffrage to women in 1914 (see Appendix G for details). Because it contains respondents' départements of birth and residence, the Generation and Gender Survey (GGS) of 2005 enables the implementation of the epidemiological approach to explore this question - importantly, this is the only survey that exists with this information. ${ }^{44}$ Since I study preferences and beliefs rather than behaviors, I do not place age restrictions on the regression sample. To apply the epidemiological approach, I focus on internal migrant respondents: 2,689 individuals, among which 1,105 men and 1,584 women. ${ }^{45}$

\footnotetext{
${ }^{44}$ See Régnier-Loilier (2016) for a description of the GGS survey. Two other datasets with information on cultural beliefs are the opinion barometer of the DRESS and the International Social Survey (ISSP), but they do not provide respondents' départements of birth.

${ }^{45}$ As with the censuses, there is no correlation between migration status and origin département
} 
Respondents were proposed three statements related to the roles of women in the labor force and asked whether they "agree," "somewhat agree," "do not agree nor disagree," "somewhat disagree," or "disagree." Statements were (1) "If a woman earns more than her partner, it is bad for their relationship," (2) "Women should not be able to decide how to spend the money they earned without asking their partners," and (3) "In an economic crisis, men should keep their jobs in priority." I assign 0 to "agree" and 1 to "disagree," and use 0.25-point increments for responses in between, so that higher values indicate more progressive attitudes toward gender roles. Then, I aggregate statements using a three-point scale, which I standardize to a one-point scale. I report average responses for men and women separately in Table 5. According to the above coding scheme, respondents "somewhat disagree" with the statements on average with an index at 0.75 , with no difference between men and women. The survey also contains questions related to preferences and beliefs about religion, marriage, and family. I report average responses relative to these statements in Tables A.8 to A.10.

Applying the same approach as before, I estimate the following specification, where I pool men and women, and further add an interaction term to assess differential influences on beliefs along genders:

$$
\begin{aligned}
\text { values }_{i b r} & =\beta_{1} \text { death_rate }_{b}+\beta_{2} \text { female }_{i}+\beta_{3} \text { death_rate } \\
& +\boldsymbol{\alpha X}_{1911, b}^{\prime}+\boldsymbol{\gamma}_{i}+\boldsymbol{\delta}_{r}+\varepsilon_{i b r},
\end{aligned}
$$

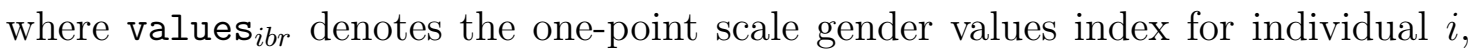
born in département $b$, and residing in département $r$. Historical controls $\mathbf{X}_{1911, b}$ are assigned at the level of départements of birth. Consistent with the epidemiological approach, I include département of residence fixed effects $\boldsymbol{\delta}_{r}$. I cluster standard errors at the levels of départements of birth and residence.

I report results in Table $6 . \quad \beta_{1}$ is identified from variations in attitudes held by respondents of the same cohort, who reside in the same département, but were born in départements that experienced different military death rates. When the interaction term is not included, $\widehat{\beta}_{1}$ is significant at the 1 percent level and implies that respondents born in départements that experienced high (20 percent) rather

military death rates, employment status, or fertility. However, internal migrants are more educated than non-migrants (Table A.7). 
than low (10 percent) military death rates hold more progressive attitudes toward female labor (column 1); the index is 11 percentage points higher in this case, which corresponds to 15 percent of the mean. Adding the interaction term does not affect $\widehat{\beta}_{1}$, but reveals a slightly stronger response of women's attitudes, though the coefficient is not significant (column 2). Adding parental and household controls and controlling for respondents' employment status, education, and fertility, does not change results substantially (columns $3-5$ ).

Estimating Specification 9 separately for each component of the gender values index reveals that the effect of military fatalities on preferences and beliefs is driven by two of its three components (Table A.11): whether respondents disagree with the statements according to which "if a woman earns more than her partner, it is detrimental for their relationship" - a strong marker of gender identity norms in relation with female labor supply (Bertrand, Kamenica and Pan, 2015) — and "in an economic crisis, men should keep their jobs in priority" - another important marker of gender norms (Alesina, Giuliano and Nunn, 2013, 524-7).

Finally, to assess whether these results reflect more progressive attitudes in general, I reproduce the analysis for attitudes related to religion, marriage, and family (Table A.12). Consistent with the original interpretation, WWI military fatalities did not impact attitudes beyond those specifically related to the roles of women in the labor force.

\section{Discussion}

One century after the First World War, the legacy of the missing men is still vivid. Comparing women who reside under similar institutional conditions but were born in départements that experienced different military death rates, I provide em-

pirical evidence for a persistent and continued impact of WWI on women's working behaviors. I uncover three channels of intergenerational transmission: parental transmission, transmission through marriage, and transmission through local social interactions. Consistent with formal models of intergenerational transmission, I find that men and women born in départements that experienced greater military death rates hold more progressive attitudes toward the role of women in the labor force today.

To take stock of these findings and put their magnitudes in perspective, I report 
the main estimates of this article together in Table 7, where I take the median whenever there are multiple estimates over time for a given specification. Finding a common ground for comparison is challenging as samples and sources of identification differ throughout. One possibility is to standardize estimates in terms of residual standard deviations. That is, rely on the effective variation in the treatment variable used for identification once fixed effects are taken into account, multiply raw estimates with these residual standard deviations, then divide them with the residual standard deviation of the outcome variable calculated in the same way (Mummolo and Peterson, 2018). To make this exercise somewhat meaningful, I compare regression coefficients estimated across samples of the same generation: first-generation migrants in Panel A, and second-generation migrants in Panel B.

Comparing magnitudes of overall effects from the epidemiological approach to those from the "inverted" epidemiological approach from Section 3.4 confirms that the legacy of the missing men operated roughly equally through intergenerational transmission than through changes to local labor market structures, echoing results from Alesina, Giuliano and Nunn (2013, 524). This also highlights the importance of the epidemiological approach in disentangling both processes. Second, another important finding is the role of marriage as an important mechanism of persistence of this historical shock, as the magnitude of the coefficient through husbands' origins is substantial (Section 4.2.1). Third, both mechanisms of social interactions appear relatively (and equally) important for persistence - though their source of variation remains markedly different from that of other analyses in this article, as it relies on cross-municipality composition variation (Section 4.3). Finally, magnitudes on preferences and beliefs are large, suggesting that changes to attitudes of both men and women are an important precondition for changes to behaviors (Section 5). Turning to analyses relying on second-generation migrants, magnitudes of estimates on mothers and mothers-in-law confirm that they were equally important agents in the transmission of the legacy of the missing men, echoing results in Fernández, Fogli and Olivetti (2004). ${ }^{46}$ In contrast, fathers appear to play a limited role in this transmission process (Sections 4.1 and 4.2.2).

Overall, these findings elucidate intergenerational diffusion pathways of women's

\footnotetext{
${ }^{46}$ The fact that these are larger than "overall" effects might be the result of the smaller amount of measurement error in these analyses, as results in Table B.2 attest.
} 
market involvement. They suggest that the entrance of women in the labor force during early phases of the revolution of female labor paved the way for subsequent generations of women, and especially their daughters and daughters-in-law. I interpret results in this article as evidence for a process of cultural diffusion and change by which women induced to enter the labor force during the interwar period because of WWI military fatalities altered preferences and beliefs about female labor of their daughters, sons, and entourage, and that these changes translated into the working behaviors of women in subsequent generations. Fernández (2013) models such a mechanism of cultural change through a framework in which women endogenously learn about the long-run payoffs of working by observing women of the previous generation. This gives rise to a sigmoid-shaped process for behaviors and beliefs about female labor. ${ }^{47}$ Providing direct empirical evidence for this feedback process is challenging as no survey traces to the interwar period. Finding innovative ways to build measures of preferences and beliefs toward female labor far back in the past to explore further this process of cultural change is a promising avenue of research.

\section{References}

Abramitzky, Ran, Adeline Delavande, and Luis Vasconcelos. 2011. "Marrying Up: The Role of Sex Ratio in Assortative Matching." American Economic Journal: Applied Economics, 3(3): 124-57.

Acemoglu, Daron, David H. Autor, and David Lyle. 2004. "Women, War, and Wages: The Effect of Female Labor Supply on the Wage Structure at Midcentury." Journal of political Economy, 112(3): 497-551.

Acemoglu, Daron, Simon Johnson, and James A. Robinson. 2005. "Institutions as a Fundamental Cause of Long-Run Growth." In Handbook of Economic Growth, Volume 1, edited by Philippe Aghion and Steven N. Durlauf, 385-472. Elsevier.

Albanesi, Stefania, and Claudia Olivetti. 2016. "Gender Roles and Medical Progress." Journal of Political Economy, 124(3): 650-95.

Alesina, Alberto, Paola Giuliano, and Nathan Nunn. 2013. "On the Origins of Gender Roles: Women and the Plough." The Quarterly Journal of Economics, 128(2): 469-530.

\footnotetext{
${ }^{47}$ See also Hazan and Maoz (2002), Fogli and Veldkamp (2011), and Hiller and Baudin (2016) for related models.
} 
Alix-Garcia, Jennifer, Laura Schechter, Felipe Valencia Caicedo, and Jessica Zhu. 2020. "Country of Women? Repercussions of the Triple Alliance War in Paraguay." CEPR Working paper 14752.

Attanasio, Orazio, Hamish Low, and Virginia Sánchez-Marcos. 2008. "Explaining Changes in Female Labor Supply in a Life-Cycle Model." The American Economic Review, 98(4): 1517-52.

Bailey, Martha J. 2006. "More Power to the Pill: The Impact of Contraceptive Freedom on Women's Life Cycle Labor Supply." The Quarterly Journal of Economics, 121(1): 289-320.

Bertrand, Marianne, Emir Kamenica, and Jessica Pan. 2015. "Gender Identity and Relative Income within Households." The Quarterly Journal of Economics, 2(130): 571-614.

Bisin, Alberto, and Thierry Verdier. 2011. "The Economics of Cultural Transmission and Socialization." In Handbook of Social Economics, Volume 1, edited by Jess Benhabib, Alberto Bisin and Matthew O. Jackson, 339-416. NorthHolland.

Blau, Francine D., Lawrence M. Kahn, and Kerry L. Papps. 2011. "Gender, Source Country Characteristics, and Labor Market Assimilation among Immigrants." The Review of Economics and Statistics, 93(1): 43-58.

Boehnke, Jörn, and Victor Gay. 2020. "The Missing Men: World War I and Female Labor Force Participation." Journal of Human Resources, forthcoming.

Boggiano, Barbara. 2020. "Long-Term Effects of the Paraguayan War (1864-1870): From Male Scarcity to Intimate Partner Violence." ZEW Working paper 20-024.

Bostrom, Alex. 2016. "Supplying the Front French Artillery Production during the First World War." French Historical Studies, 39(2): 261-86.

Boulanger, Philippe. 2001. La France Devant la Conscription: Géographie Historique d'une Institution Républicaine, 1914-1922. Paris: Economica.

Brilhault, Gwennaëlle, and Nathalie Caron. 2016. "Le Passage à une Collecte par Sondage: Quel Impact sur la Précision du Recensement ?" Economie et Statistique, 483-5: 23-40.

Bütikofer, Aline. 2013. "Revisiting 'Mothers and Sons' Preference Formation and the Female Labor Force in Switzerland." Labour Economics, 20: 82-91.

Campos-Vazquez, Raymundo Miguel, and Roberto Velez-Grajales. 2014. "Female Labour Supply and Intergenerational Preference Formation: Evidence for Mexico." Oxford Development Studies, 42(4): 553-69.

Cantoni, Davide, Felix Hagemeister, and Mark Westcott. 2020. "Persistence and Activation of Right-Wing Political Ideology."

Cardoso, Ana Rute, and Louis-Philippe Morin. 2018. "Can Economic Pressure Overcome Social Norms? The Case of Female Labor Force Participation." IZA Working paper 11822. 
Chen, Xi Chen, and Suqin Ge. 2018. "Social Norms and Female Labor Force Participation in Urban China." Journal of Comparative Economics, 46(4): 966-87.

Clemens, Michael A. 2017. "The Meaning of Failed Replications: A Review and Proposal." Journal of Economic Surveys, 31(1): 326-42.

Doepke, Matthias, Moshe Hazan, and Yishay D. Maoz. 2015. "The Baby Boom and World War II: A Macroeconomic Analysis." The Review of Economic Studies, 82(3): 1031-73.

Farre, Lidia, and Francis Vella. 2013. "The Intergenerational Transmission of Gender Role Attitudes and its Implications for Female Labour Force Participation." Economica, 80(318): 219-47.

Fernández, Raquel. 2011. "Does Culture Matter?" In Handbook of Social Economics, Volume 1, edited by Jess Benhabib, Alberto Bisin and Matthew O. Jackson, 481-510. North-Holland.

Fernández, Raquel. 2013. "Cultural Change as Learning: The Evolution of Female Labor Force Participation Over a Century." The American Economic Review, 103(1): 472-500.

Fernández, Raquel, Alessandra Fogli, and Claudia Olivetti. 2004. "Mothers and Sons: Preference Formation and Female Labor Force Dynamics." The Quarterly Journal of Economics, 119(4): 1249-99.

Fernández, Raquel, and Alessandra Fogli. 2009. "Culture: An Empirical Investigation of Beliefs, Work, and Fertility." American Economic Journal: Macroeconomics, 1(1): 146-77.

Ferrara, Andreas. 2020. "World War II and Black Economic Progress." CAGE Warwick Working paper 387.

Fogli, Alessandra, and Laura Veldkamp. 2011. "Nature or Nurture? Learning and the Geography of Female Labor Force Participation." Econometrica, 79(4): 1103-38.

Fouka, Vasiliki, and Hans-Joachim Voth. 2020. "Collective Remembrance and Private Choice: German-Greek Conflict and Consumer Behavior in Times of Crisis."

Gay, Victor. 2021. "Mapping the Third Republic. A Geographic Information System of France (1870-1940)." Historical Methods: A Journal of Quantitative and Interdisciplinary History, forthcoming.

Gay, Victor, Daniel L. Hicks, Estefania Santacreu-Vasut, and Amir Shoham. 2018. "Decomposing Culture: An Analysis of Gender, Language, and Labor Supply in the Household." Review of Economics of the Household, 16(4): 879-909.

Girard, Alain, Henri Bastide, and Guy Pourcher. 1964. "Mobilité Géographique et Concentration Urbaine en France. Une Enquête en Province." Population, 19(2): 227-66. 
Giuliano, Paola. 2017. "Gender: A Historical Perspective." In The Oxford Handbook of Women and the Economy, edited by Susan L. Averett, Laura M. Argys and Saul D. Hoffman. New York: Oxford University Press.

Giuliano, Paola, and Nathan Nunn. 2020. "Understanding Cultural Persistence and Change." Review of Economic Studies, Forthcoming.

Goldin, Claudia. 1990. Understanding the Gender Gap: An Economic History of American Women. New York: Oxford University Press.

Goldin, Claudia. 2006. "The Quiet Revolution That Transformed Women's Employment, Education, and Family." American Economic Review, 96(2): 1-21.

Goldin, Claudia. 2014. "A Grand Gender Convergence: Its Last Chapter." The American Economic Review, 104(4): 1091-119.

Goldin, Claudia, and Claudia Olivetti. 2013. "Shocking Labor Supply: A Reassessment of the Role of World War II on Women's Labor Supply." The American Economic Review, 103(3): 257-62.

Gonzalez-Feliu, Jesus, and Antoine Parent. 2016. "Clio-Combinatorics: A Novel Framework to Analyze Military Logistics Choices Using Operations Research Techniques." In Handbook of Research on Military, Aeronautical, and Maritime Logistics and Operations, edited by Alberto Ochoa-Zazzatti, Jöns Sánchez, Miguel G. Cedillo-Campos and Margain de Lourdes, 79-101. Hershey, PA: IGI Global.

Greenwood, Jeremy, Ananth Seshadri, and Mehmet Yorukoglu. 2005. "Engines of Liberation." The Review of Economic Studies, 72(1): 109-33.

Grosjean, Pauline, and Rose Khattar. 2019. "It's Raining Men! Hallelujah? The Long-Run Consequences of Male-Biased Sex Ratios." The Review of Economic Studies, 86(2): 723-54.

Hauk, Esther, and Maria Saez-Marti. 2002. "On the Cultural Transmission of Corruption." Journal of Economic Theory, 107(2): 311-35.

Hazan, Moshe, and Yishay D. Maoz. 2002. "Women's Labor Force Participation and the Dynamics of Tradition." Economics Letters, 75(2): 193-8.

Hiller, Victor, and Thomas Baudin. 2016. "Cultural Transmission and the Evolution of Gender Roles." Mathematical Social Sciences, 84: 8-23.

Huber, Michel. 1931. La Population de la France Pendant la Guerre. Yale University Press.

Johnston, David W., Stefanie Schurer, and Michael A. Shields. 2014. "Maternal Gender Role Attitudes, Human Capital Investment, and Labour Supply of Sons and Daughters." Oxford Economic Papers, 66(3): 631-59.

Kawaguchi, Daiji, and Junko Miyazaki. 2009. "Working Mothers and Sons' Preferences Regarding Female Labor Supply: Direct Evidence from Stated Preferences." Journal of Population Economics, 22(1): 115-30.

Lagrou, Pieter. 2002. "Les Guerres, les Morts et le Deuil: Bilan Chiffré de la Seconde Guerre Mondiale." In La Violence de Guerre, 1914-1945. Approches Com- 
parées des Deux Conflits Mondiaux, edited by Stéphane Audouin-Rouzeau, Annette Becker, Christian Ingrao and Henry Rousso, 313-27. Bruxelles: Complexe; Paris: IHTP-CNRS.

Li, Zhongda, and Lu Liu. 2018. "Preference or Endowment? Intergenerational Transmission of Women's Work Behavior and the Underlying Mechanisms." Journal of Population Economics, 1-35.

Maruani, Margaret, and Monique Meron. 2012. Un Siècle de Travail des Femmes en France: 1901-2011. Paris: La Découverte.

Michalopoulos, Stelios, and Elias Papaioannou. 2017. The Long Economic and Political Shadow of History. London: CEPR Press.

Michalopoulos, Stelios, Louis Putterman, and David N. Weil. 2019. "The Influence of Ancestral Lifeways on Individual Economic Outcomes in Sub-Saharan Africa." Journal of the European Economic Association, 17(4): 1186-231.

Morrill, Melinda Sandler, and Thayer Morrill. 2013. "Intergenerational Links in Female Labor Force Participation." Labour Economics, 20: 38-47.

Mummolo, Jonatha, and Erik Peterson. 2018. "Improving the Interpretation of Fixed Effects Regression Results." Political Science Research and Methods, 6(4): 829-35.

Ngai, Rachel L., and Barbara Petrongolo. 2017. "Gender Gaps and the Rise of the Service Economy." American Economic Journal: Macroeconomics, 9(4): 1-44.

Nunn, Nathan. 2014. "Historical Development." In Handbook of Economic Growth, Volume 2, edited by Philippe Aghion and Steven N. Durlauf, 347-402. Elsevier.

Nunn, Nathan, and Leonard Wantchekon. 2011. "The Slave Trade and the Origins of Mistrust in Africa." American Economic Review, 101(7): 3221-52.

Ochsner, Christian, and Felix Roesel. 2019. "Mobilizing History."

Olivetti, Claudia, and Barbara Petrongolo. 2016. "The Evolution of Gender Gaps in Industrialized Countries." Annual Review of Economics, 8: 405-34.

Olivetti, Claudia, Eleonora Patacchini, and Yves Zenou. 2020. "Mothers, Peers, and Gender-Role Identity." Journal of the European Economic Association, 18(1): 266-301.

Porte, Rémy. 2005. La Mobilisation Industrielle: 'Premier Front' de la Grande Guerre? Paris: 14-18 Éditions.

Prost, Antoine. 2008. "Compter les Vivants et les Morts: l'Évaluation des Pertes Françaises de 1914-1918." Le Mouvement Social, 222(1): 41-60.

Régnier-Loilier, Arnaud. 2016. Parcours de Familles: L'Enquête Etude des Relations Familiales et Intergénérationnelles. Paris: INED. 
Rose, Evan K. 2018. "The Rise and Fall of Female Labor Force Participation During World War II in the United States." The Journal of Economic History, 78(3): 673-711.

Teso, Edoardo. 2019. "The Long-Term Effect of Demographic Shocks on the Evolution of Gender Roles: Evidence from the transatlantic Slave Trade." Journal of the European Economic Association, 17(2): 497-534.

Vandenbroucke, Guillaume. 2014. "Fertility and Wars: the Case of World War I in France." American Economic Journal: Macroeconomics, 6(2): 108-36. 


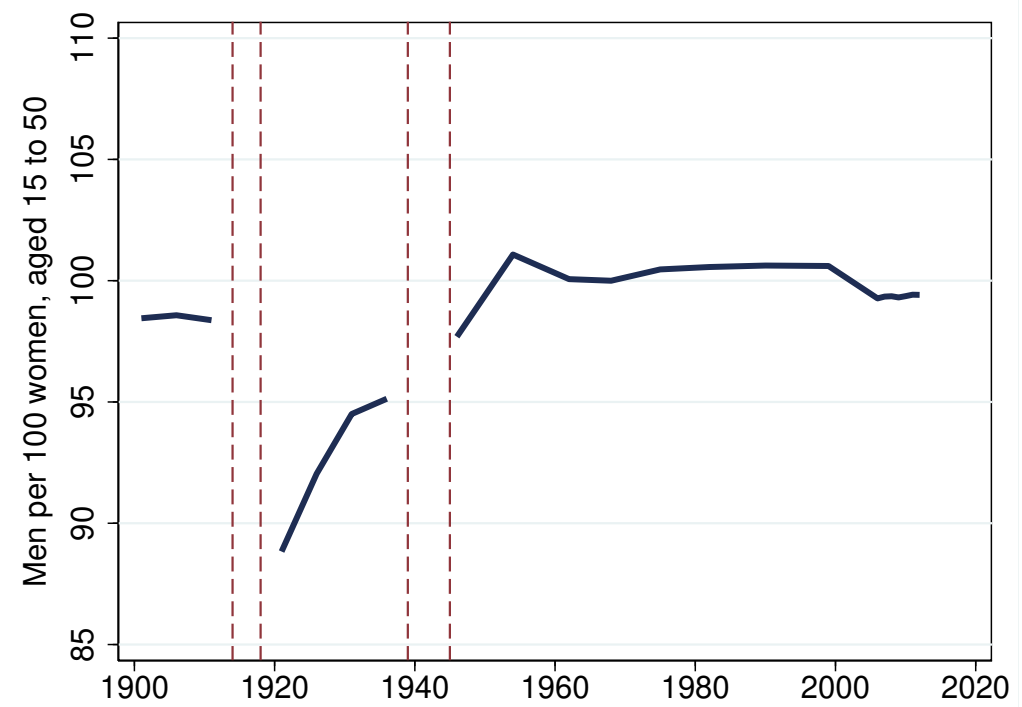

Figure 1. Adult Sex Ratio (1900-2012)

Notes: This figure displays the sex ratio among French adults aged 15 to 50. Data are from the censuses 1901-2012. Vertical lines indicate WWI (1914-1918) and WWII (1939-1945).

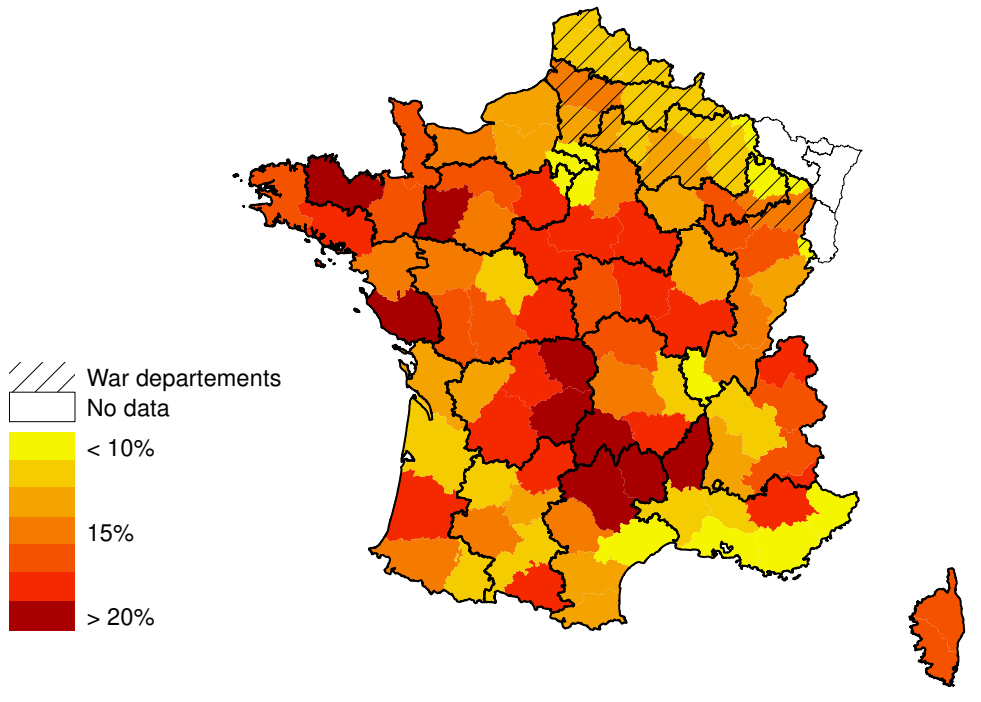

Figure 2. Military Death Rates Across 87 Départements

Notes: Data are missing for the three départements that belonged to Germany before WWI-BasRhin, Haut-Rhin, and Moselle. Shaded areas indicates départements in which war combats occurred. Darker lines indicate military region boundaries. The composition of each military region is from the Journal Officiel de la République Française, Lois et Décrets, 45(261), 8546-8547, September 26, 1913. Shapefiles are from Gay (2021). 


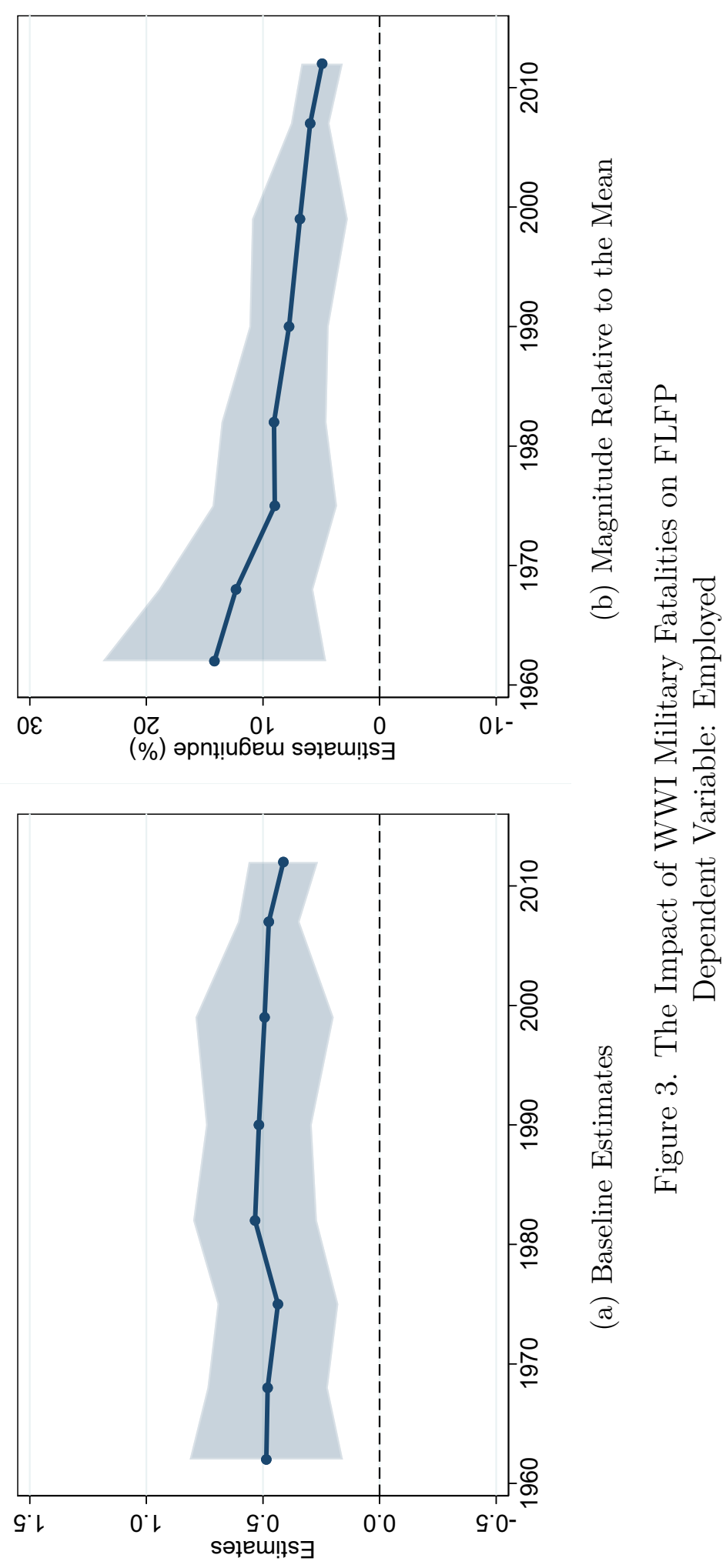

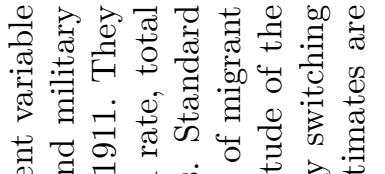

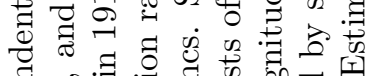

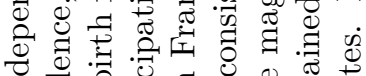

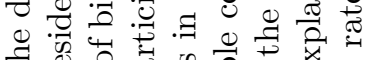
F

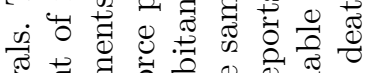

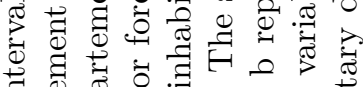

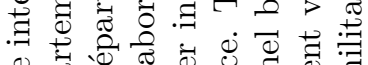
ช

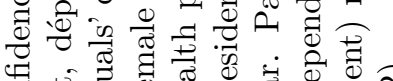

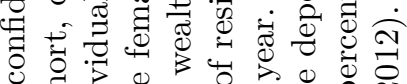
용 ๑ี

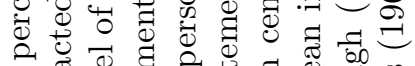
ฉ.

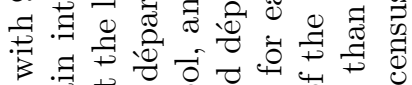

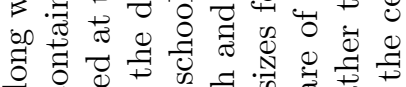

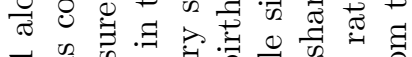
च 苟 0

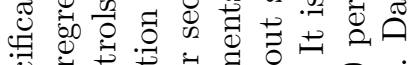

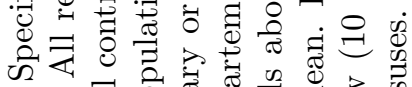

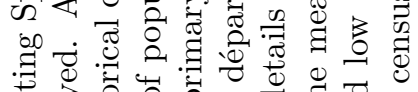
范

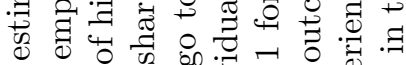
घ.

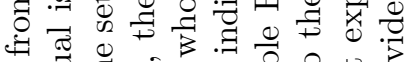

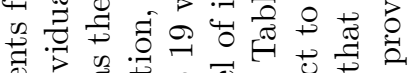

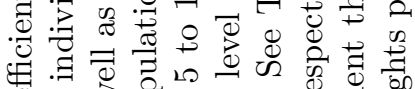

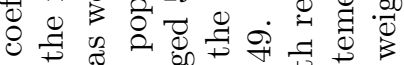

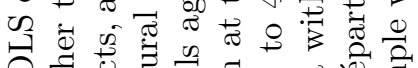

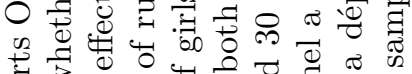

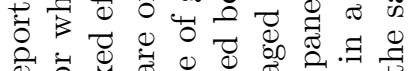

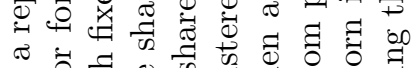

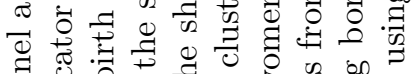

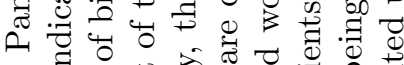

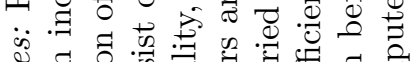

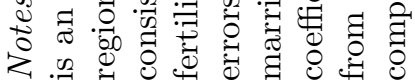




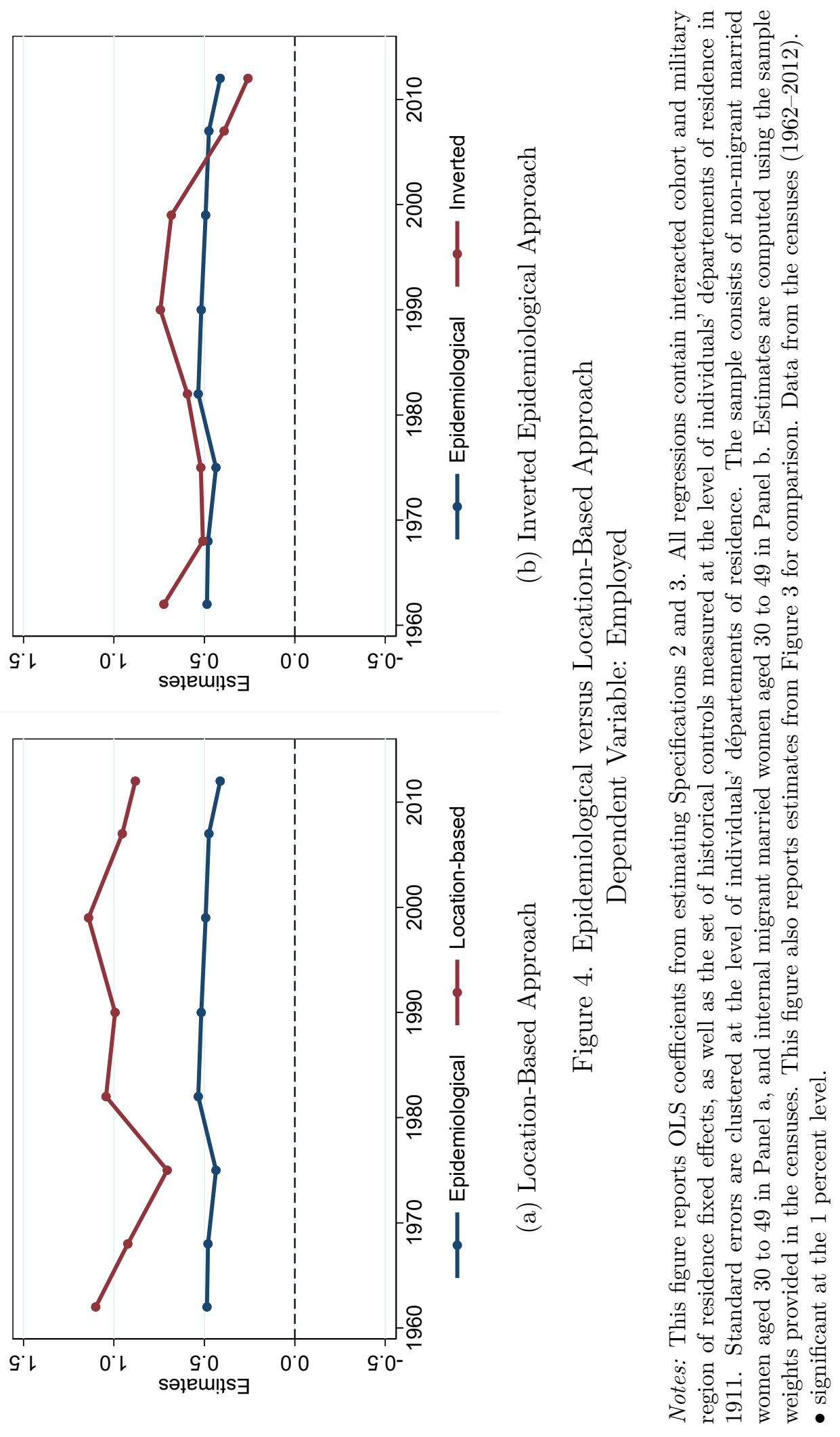



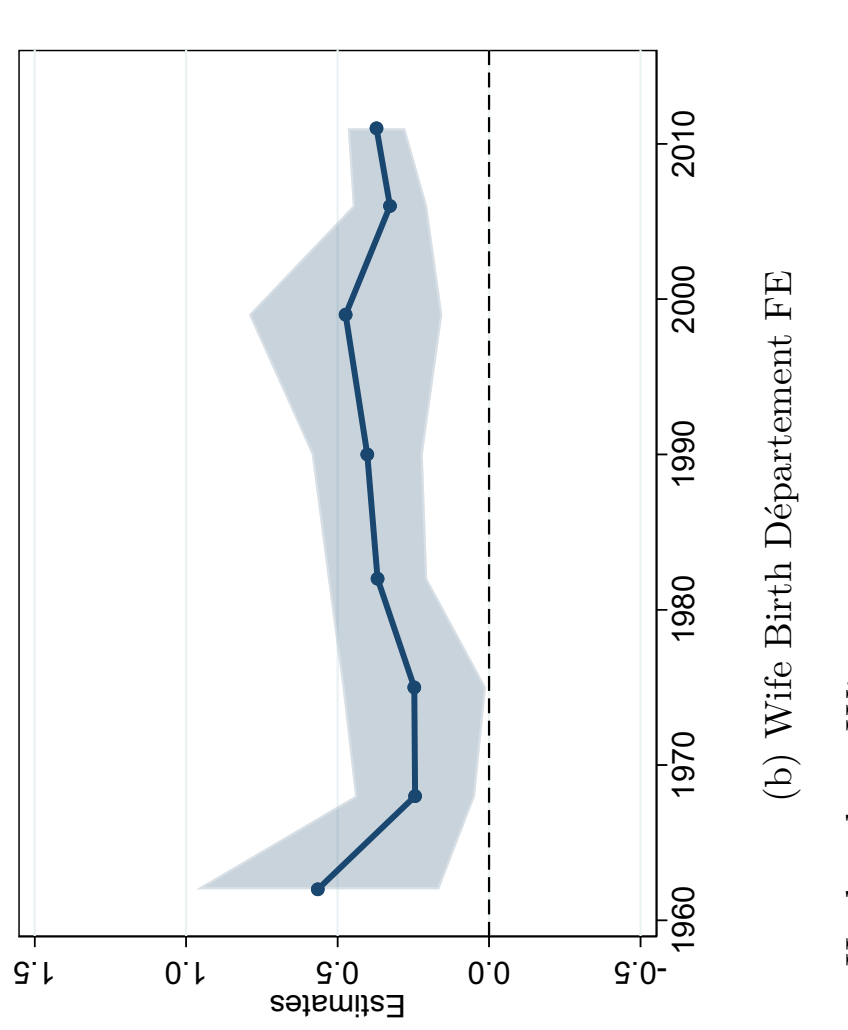

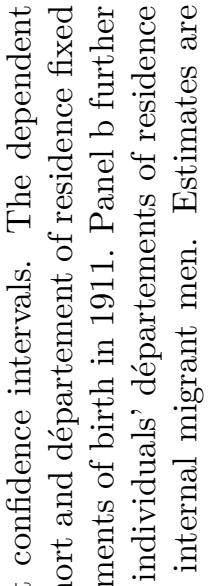

Q

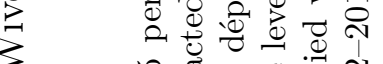

28

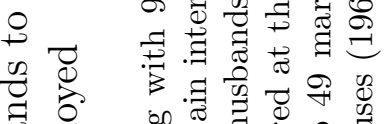

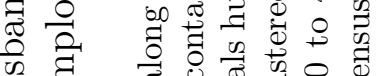

疍

वี

5. $\cong$ क

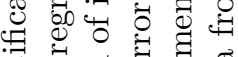

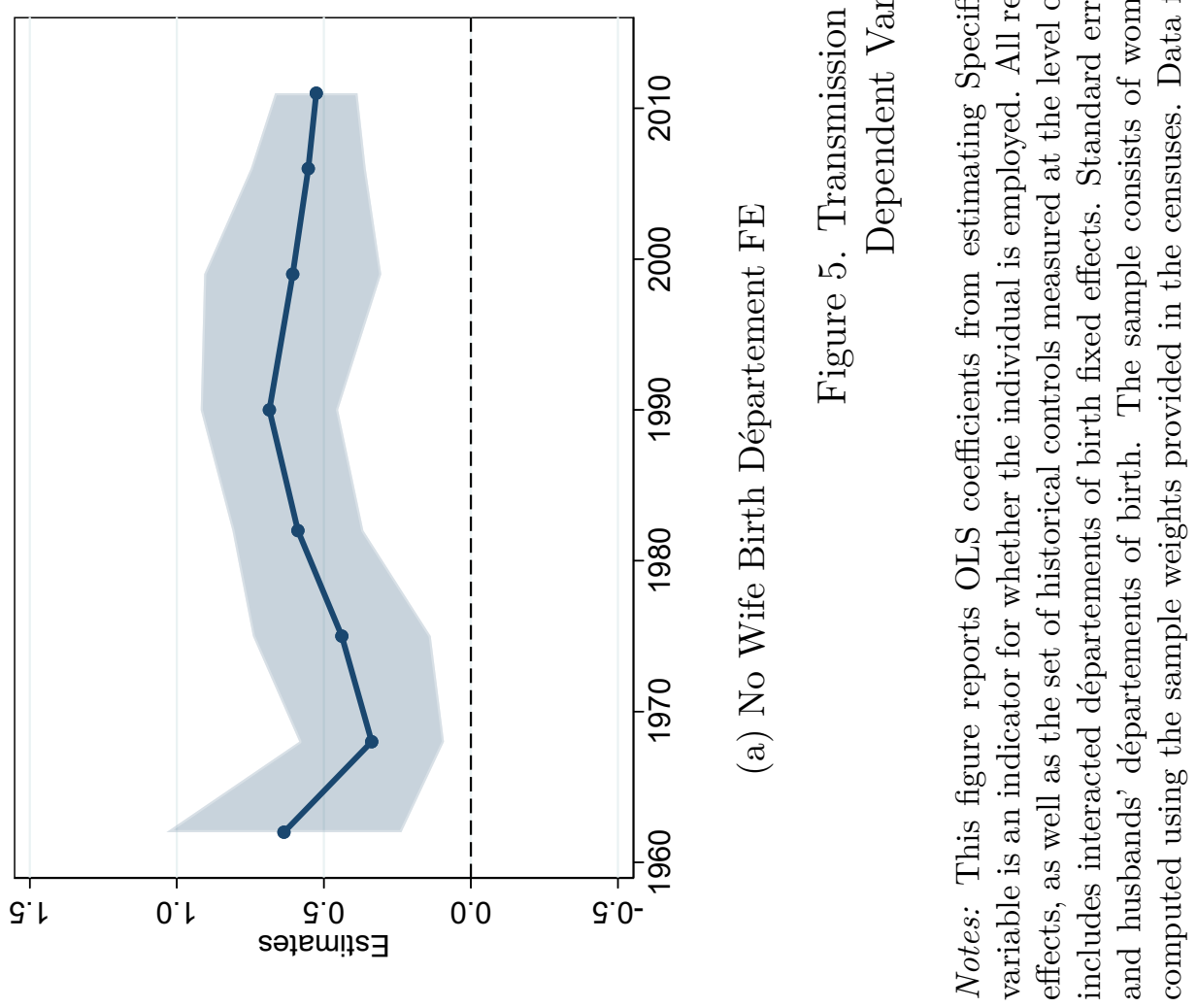




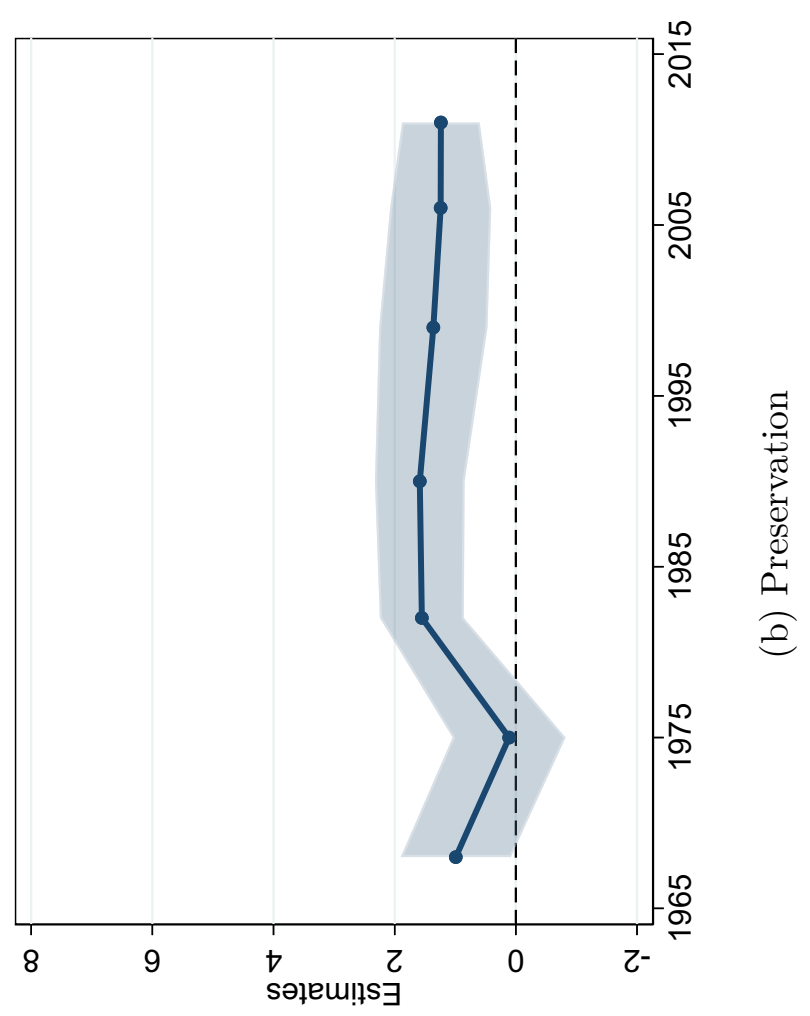

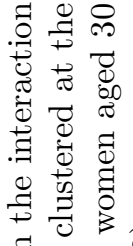

范

赵范

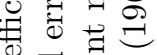

词范

थ :

○需 శี

बे

ॠ

ค 월.

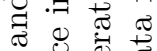

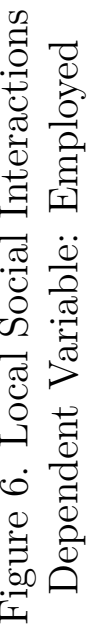

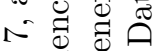

a c

苛

或嵌

递 is

की

$\because 200$

고웡

施

đ)

है 유

$\exists \infty^{-} H$

है

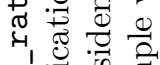

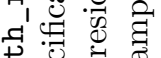

远

कै की

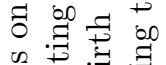

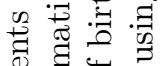

. ․ㅢ

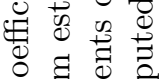

ठ

杄

00

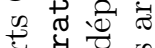

क्ष 0

㐘

ช

$\overrightarrow{0} \times \vec{b}$

ฮี है

$\because$ की

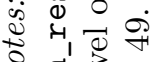

之它完。 
Table 1. Military Death Rates and Pre-War Characteristics

\begin{tabular}{lccc}
\hline \hline \multirow{2}{*}{ Dependent variable } & \multicolumn{3}{c}{ Military death rate } \\
\cline { 2 - 4 } & $(1)$ & $(2)$ & $(3)$ \\
\hline Share rural population & $0.12^{* * *}$ & $0.12^{* * *}$ & $0.14^{* * *}$ \\
Share born in département & {$[0.01]$} & {$[0.02]$} & {$[0.03]$} \\
& $0.12^{* * *}$ & $0.13^{* * *}$ & $0.16^{* * *}$ \\
Female labor force participation & {$[0.03]$} & {$[0.03]$} & {$[0.04]$} \\
& & -0.02 & 0.04 \\
Share girls aged 5-19 in school & & {$[0.04]$} & {$[0.04]$} \\
& & 0.09 & 0.10 \\
Total fertility rate & & $0.07]$ & {$[0.08]$} \\
& & {$[0.00]$} & $0.00 *$ \\
Personal wealth (thousand francs) & & $0.00^{* *}$ & $0.00]$ \\
& & {$[0.00]$} & {$[0.00]$} \\
Other characteristics & & & \\
Military region FE & No & Yes & Yes \\
Départements & No & No & Yes \\
$\mathrm{R}^{2}$ & & & \\
\hline
\end{tabular}

Notes: This table reports OLS coefficients from regressing military death rates on various pre-war département characteristics measured in 1911. Other characteristics include average height, population, the share of men working in industry, in agriculture, the share of the literate population, and the average direct taxes per inhabitant. The coefficient on total fertility rate is a precise zero (0.00002, standard error of 0.00001). Robust standard errors are in brackets.

*** Significant at the 1 percent level. ${ }^{* *}$ Significant at the 5 percent level. * Significant at the 10 percent level. 
Table 2. Transmission from Mothers to Daughters

Extended Labor Force Surveys 2005-2012

\begin{tabular}{lccccc}
\hline \hline Dependent variable & \multicolumn{5}{c}{ Employed } \\
\cline { 2 - 6 } & $(1)$ & $(2)$ & $(3)$ & $(4)$ & $(5)$ \\
\hline Military death rate (mother) & $1.05^{* * *}$ & $0.93^{* *}$ & $1.11^{* * *}$ & $1.24^{* * *}$ & $0.94^{* * *}$ \\
& {$[0.37]$} & {$[0.40]$} & {$[0.40]$} & {$[0.35]$} & {$[0.34]$} \\
& & & & & \\
Father birth département FE & No & Yes & Yes & Yes & No \\
Mother birth region FE & No & No & Yes & Yes & No \\
Other controls & No & No & No & Yes & No \\
Clusters & & & & & \\
$\quad$ Own birth-residence & 95 & 95 & 95 & 95 & 95 \\
$\quad$ Mother birth & 95 & 95 & 95 & 95 & 95 \\
& & & & & \\
Observations & 15,095 & 15,095 & 15,095 & 15,095 & 32,099 \\
& & & & & \\
Outcome mean & 0.81 & 0.81 & 0.81 & 0.81 & 0.79 \\
Outcome s.d. & 0.39 & 0.39 & 0.39 & 0.39 & 0.40 \\
\hline
\end{tabular}

Notes: This table reports the OLS coefficients from estimating Specification 4. All regressions contain cohort, département of birth and residence, and survey-year fixed effects, as well as the set of historical controls measured at the level of individuals' mothers' départements of birth in 1911. Other controls include parental characteristics (indicators for parents' occupational status and mothers' labor status), husband and household characteristics (husbands' incomes, age, age squared, educational attainment, an indicator for home ownership, and the number of rooms in the home), and individuals' education and number of children. Standard errors are clustered at the level of départements of residence and mothers' départements of birth. The sample consists of non-migrant married women aged 30 to 59 whose mothers and fathers were born in another département in columns 1-4, and whose mothers (but not necessarily fathers) were born in another département in column 5. Estimates are computed using the sample weights provided in the extended labor force surveys.

${ }^{* * *}$ Significant at the 1 percent level. ${ }^{* *}$ Significant at the 5 percent level. 
Table 3. Transmission from Mothers to Daughters, 2SLS

Extended Labor Force Surveys 2005-2012

\begin{tabular}{|c|c|c|c|c|c|c|}
\hline \multirow[t]{3}{*}{ Dependent variable } & \multirow{2}{*}{\multicolumn{3}{|c|}{$\begin{array}{l}\text { Mother worked } \\
\text { A. First Stage }\end{array}$}} & \multirow{2}{*}{\multicolumn{3}{|c|}{$\frac{\text { Employed }}{\text { B. Second Stage }}$}} \\
\hline & & & & & & \\
\hline & (1) & $(2)$ & $(3)$ & $(4)$ & $(5)$ & $(6)$ \\
\hline Military death rate (mother) & $\begin{array}{c}1.39^{* * *} \\
{[0.53]}\end{array}$ & $\begin{array}{c}1.94^{* * *} \\
{[0.64]}\end{array}$ & $\begin{array}{c}1.80^{* * *} \\
{[0.61]}\end{array}$ & & & \\
\hline Mother worked & & & & $\begin{array}{c}0.76^{* *} \\
{[0.38]}\end{array}$ & $\begin{array}{c}0.49^{* *} \\
{[0.23]}\end{array}$ & $\begin{array}{c}0.49^{* *} \\
{[0.24]}\end{array}$ \\
\hline Father birth département FE & No & Yes & Yes & No & Yes & Yes \\
\hline Other controls & No & No & Yes & No & No & Yes \\
\hline \multicolumn{7}{|l|}{ Clusters } \\
\hline Own birth-residence & 95 & 95 & 95 & 95 & 95 & 95 \\
\hline Mother birth & 95 & 95 & 95 & 95 & 95 & 95 \\
\hline Observations & 15,095 & 15,095 & 15,095 & 15,095 & 15,095 & 15,095 \\
\hline Outcome mean & 0.59 & 0.59 & 0.59 & 0.81 & 0.81 & 0.81 \\
\hline Outcome s.d. & 0.49 & 0.49 & 0.49 & 0.39 & 0.39 & 0.39 \\
\hline F-statistic & 29.70 & 44.38 & 38.49 & & & \\
\hline
\end{tabular}

Notes: All regressions contain cohort, département of birth and residence, and survey-year fixed effects, as well as the set of historical controls measured at the level of individuals' mothers' départements of birth in 1911. Other controls include parental characteristics (indicators for parents' occupational status and mothers' labor status), husband and household characteristics (husbands' incomes, age, age squared, educational attainment, an indicator for home ownership, and the number of rooms in the home), and individuals' education and number of children. Standard errors are clustered at the level of the départements of birth and mothers départements of birth. The sample consists of non-migrant married women aged 30 to 59 whose mothers and fathers were born in another département. The estimates are computed using the sample weights provided in the extended labor force surveys.

${ }^{* * *}$ Significant at the 1 percent level. ${ }^{* *}$ Significant at the 5 percent level. ${ }^{*}$ Significant at the 1 percent level. 
Table 4. Transmission from Mothers-In-Law to Daughters-In-Law Extended Labor Force Surveys 2005-2012

\begin{tabular}{lcccc}
\hline \hline \multirow{2}{*}{ Dependent variable } & \multicolumn{4}{c}{ Employed } \\
\cline { 2 - 5 } & $(1)$ & $(2)$ & $(3)$ & $(4)$ \\
\hline Military death rate (mother-in-law) & $1.28^{*}$ & $1.20^{*}$ & $1.48^{* *}$ & $1.64^{* *}$ \\
& {$[0.75]$} & {$[0.61]$} & {$[0.65]$} & {$[0.66]$} \\
& & & & \\
Own parents birth département FE & No & Yes & Yes & Yes \\
Mother-in-law birth region FE & No & No & Yes & Yes \\
Other controls & No & No & No & Yes \\
& & & & \\
Clusters & & & & \\
$\quad$ Own birth-residence & 94 & 94 & 94 & 94 \\
$\quad$ Mother -in-law birth & 94 & 94 & 94 & 94 \\
& & & & \\
Observations & 13,389 & 13,389 & 13,389 & 13,389 \\
Outcome mean & & & & \\
Outcome s.d. & 0.81 & 0.81 & 0.81 & 0.81 \\
\hline
\end{tabular}

Notes: This table reports the OLS coefficients from estimating Specification 4 augmented with fixed effects for both own parents' and husbands' départements of birth. All regressions contain cohort, département of birth and residence, husband birth département, and survey-year fixed effects, as well as the set of historical controls measured at the level of individuals' mothersin-law's départements of birth in 1911. Other controls include parental characteristics (indicators for parents' occupational status and mothers' labor status), husband and household characteristics (husbands' incomes, age, age squared, educational attainment, an indicator for home ownership, and the number of rooms in the home), and individuals' education and number of children. Standard errors are clustered at the level of départements of residence and mothers-in-law's départements of birth. The sample consists of non-migrant married women aged 30 to 59 whose mothers and fathers were born in another département. Estimates are computed using the sample weights provided in the extended labor force surveys.

${ }^{* *}$ Significant at the 5 percent level. ${ }^{*}$ Significant at the 10 percent level. 
Table 5. Preferences and Beliefs About Female Labor

Higher values mean disagreement with the statement

\begin{tabular}{|c|c|c|c|c|}
\hline & & \multicolumn{3}{|c|}{ Sex of respondent } \\
\hline & & All & Men & Women \\
\hline 1 & $\begin{array}{l}\text { If a woman earns more than her } \\
\text { partner, it is detrimental for their relationship }\end{array}$ & $\begin{array}{c}0.78 \\
(0.29)\end{array}$ & $\begin{array}{c}0.80 \\
(0.27)\end{array}$ & $\begin{array}{c}0.76 \\
(0.31)\end{array}$ \\
\hline 2 & $\begin{array}{l}\text { Women should not decide how to spend } \\
\text { the money they earned without asking } \\
\text { their partners }\end{array}$ & $\begin{array}{c}0.73 \\
(0.34)\end{array}$ & $\begin{array}{c}0.70 \\
(0.35)\end{array}$ & $\begin{array}{c}0.76 \\
(0.34)\end{array}$ \\
\hline 3 & $\begin{array}{l}\text { In an economic crisis, men should } \\
\text { keep their jobs in priority }\end{array}$ & $\begin{array}{c}0.74 \\
(0.35)\end{array}$ & $\begin{array}{c}0.72 \\
(0.35)\end{array}$ & $\begin{array}{c}0.76 \\
(0.35)\end{array}$ \\
\hline & $\begin{array}{l}\text { ender values index } \\
\text { hree-point scale) }\end{array}$ & $\begin{array}{c}2.25 \\
(0.64)\end{array}$ & $\begin{array}{c}2.22 \\
(0.63)\end{array}$ & $\begin{array}{c}2.27 \\
(0.65)\end{array}$ \\
\hline & $\begin{array}{l}\text { ender values index } \\
\text { ne-point scale) }\end{array}$ & $\begin{array}{c}0.75 \\
(0.21)\end{array}$ & $\begin{array}{c}0.74 \\
(0.21)\end{array}$ & $\begin{array}{c}0.76 \\
(0.22)\end{array}$ \\
\hline & bservations & 2,689 & 1,105 & 1,584 \\
\hline
\end{tabular}

Notes: This table reports summary statistics for preferences and beliefs about female labor on the sample of internal migrant respondents. Higher values indicate disagreement with the statement. Standard deviations are in parenthesis. Data from the GGS (2005). 
Table 6. The Impact of WWI Military Fatalities on Beliefs

\begin{tabular}{lccccc}
\hline \hline \multirow{2}{*}{ Dependent variable } & \multicolumn{5}{c}{ Gender values index (one-point scale) } \\
\cline { 2 - 6 } & $(1)$ & $(2)$ & $(3)$ & $(4)$ & $(5)$ \\
\hline Military death rate & $1.14^{* * *}$ & $1.04^{* * *}$ & $0.95^{* * *}$ & $0.96^{* * *}$ & $1.00^{* * *}$ \\
& {$[0.21]$} & {$[0.31]$} & {$[0.32]$} & {$[0.32]$} & {$[0.33]$} \\
Female & $0.02^{*}$ & -0.01 & -0.01 & -0.01 & -0.01 \\
& {$[0.01]$} & {$[0.03]$} & {$[0.03]$} & {$[0.03]$} & {$[0.03]$} \\
Military death rate $\times$ Female & & 0.16 & 0.20 & 0.17 & 0.22 \\
& & {$[0.21]$} & {$[0.20]$} & {$[0.20]$} & {$[0.21]$} \\
Controls & & & & & \\
Parental & No & No & Yes & Yes & Yes \\
Household & No & No & No & Yes & Yes \\
Individual & No & No & No & No & Yes \\
Clusters & & & & & \\
Residence & & & & & \\
Birth département & 95 & 95 & 95 & 95 & 95 \\
Observations & 88 & 88 & 88 & 88 & 88 \\
Outcome mean & 2,688 & 2,688 & 2,688 & 2,688 & 2,688 \\
\hline
\end{tabular}

Notes: This table reports the OLS coefficients from estimating Specification 9. All regressions contain cohort and département of residence fixed effects, as well as the set of historical controls measured at the level of respondents' départements of birth in 1911. Household controls include an indicator for whether the respondent's home is a house rather than an apartment, the number of rooms in the home, an indicator for whether the respondent owns her housing, and an indicator for whether the respondent has a partner present in the household. Parental controls include the labor status of the respondent's mother, and educational attainment indicators for both parents. Individual controls include employment status, educational attainment, and the number of children in the household. Standard errors are clustered at the level of départements of birth and of residence. The sample consists of internal migrants. The estimates are computed using the sample weights provided in the GSS. Data from the GSS (2005).

*** Significant at the 1 percent level. 


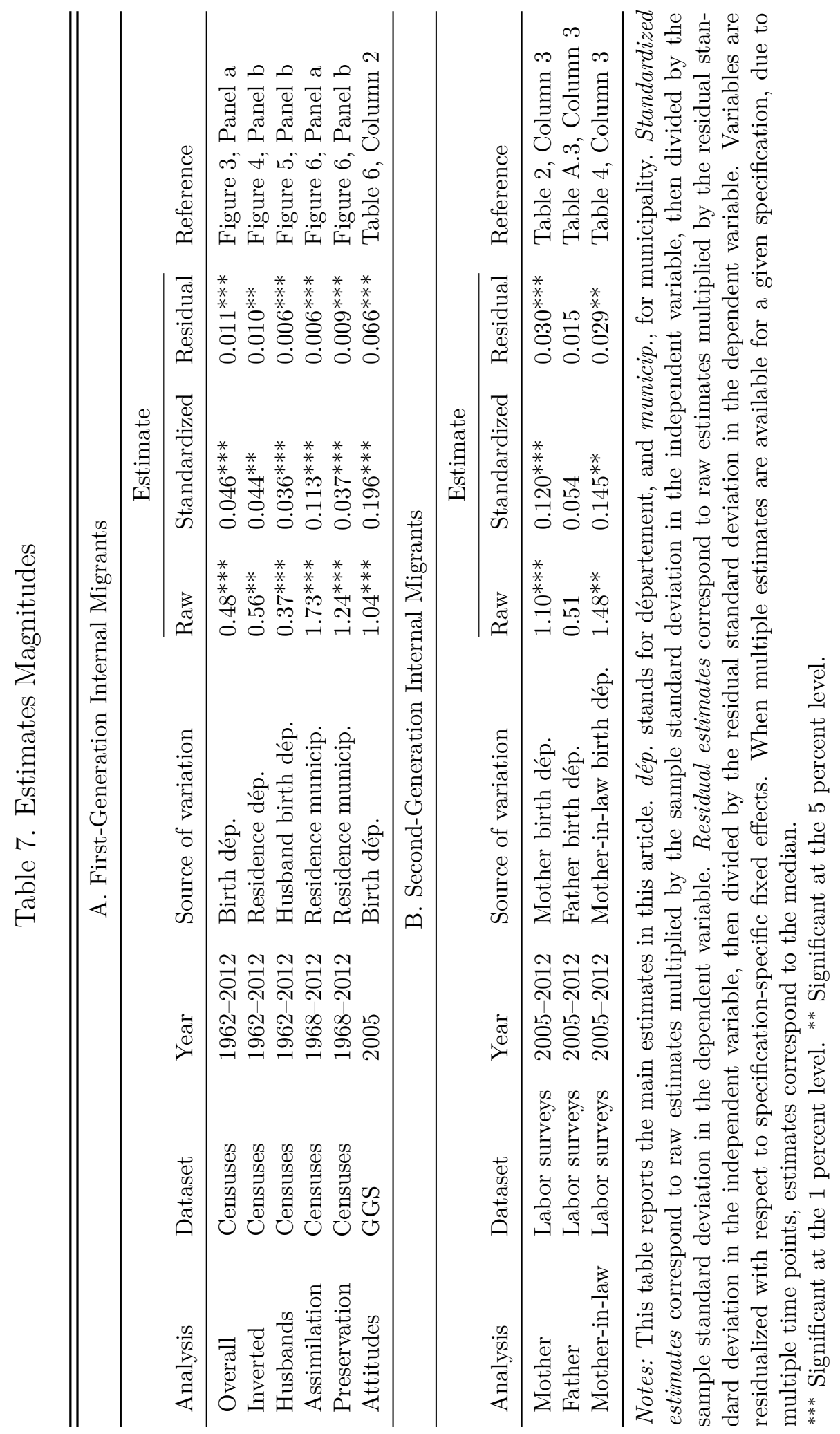

